\title{
Nuclear localization of Newcastle disease virus matrix protein promotes virus replication by affecting viral RNA synthesis and transcription and inhibiting host cell transcription
}

\author{
Zhiqiang Duan ${ }^{1,2^{*}}$, Shanshan Deng ${ }^{2}$, Xinqin Ji ${ }^{1,2}$, Jiafu Zhao ${ }^{1,2}$, Chao Yuan ${ }^{1,2}$ and Hongbo Gao ${ }^{1,2}$
}

\begin{abstract}
Nuclear localization of paramyxovirus proteins is crucial for virus life cycle, including the regulation of viral replication and the evasion of host immunity. We previously showed that a recombinant Newcastle disease virus (NDV) with nuclear localization signal mutation in the matrix (M) protein results in a pathotype change and attenuates viral pathogenicity in chickens. However, little is known about the nuclear localization functions of NDV M protein. In this study, the potential functions of the $\mathrm{M}$ protein in the nucleus were investigated. We first demonstrate that nuclear localization of the M protein could not only promote the cytopathogenicity of NDV but also increase viral RNA synthesis and transcription efficiency in DF-1 cells. Using microarray analysis, we found that nuclear localization of the M protein might inhibit host cell transcription, represented by numerous up-regulating genes associated with transcriptional repressor activity and down-regulating genes associated with transcriptional activator activity. The role of representative up-regulated gene prospero homeobox 1 (PROX1) and down-regulated gene aryl hydrocarbon receptor (AHR) in the replication of NDV was then evaluated. The results show that siRNA-mediated knockdown of PROX1 or AHR significantly reduced or increased the viral RNA synthesis and viral replication, respectively, demonstrating the important roles of the expression changes of these genes in NDV replication. Together, our findings demonstrate for the first time that nuclear localization of NDV M protein promotes virus replication by affecting viral RNA synthesis and transcription and inhibiting host cell transcription, improving our understanding of the molecular mechanism of NDV replication and pathogenesis.
\end{abstract}

\section{Introduction}

Paramyxoviruses describe a family of non-segmented negative-sense RNA viruses (NNSV) responsible for significant human and animal diseases, such as measles virus $(\mathrm{MeV})$, mumps virus $(\mathrm{MuV})$, Nipah virus $(\mathrm{NiV})$, Hendra virus $(\mathrm{HeV})$, Sendai virus $(\mathrm{SeV})$, parainfluenza virus types $1-5$, and Newcastle disease virus (NDV) [1].

*Correspondence: zqduan@gzu.edu.cn

${ }^{1}$ Key Laboratory of Animal Genetics, Breeding and Reproduction in The Plateau Mountainous Region, Ministry of Education, Guizhou University, Guiyang, China

Full list of author information is available at the end of the article
The RNA genomes of paramyxoviruses are $15-19 \mathrm{~kb}$ in length and contain six to ten genes that encode six structural viral proteins, including fusion protein $(\mathrm{F})$, attachment protein ( $\mathrm{HN}$ or $\mathrm{H}$ or $\mathrm{G})$, nucleocapsid protein $(\mathrm{N}$ or $\mathrm{NP})$, phosphoprotein protein (P), large polymerase protein $(\mathrm{L})$, matrix protein $(\mathrm{M})[2,3]$. Of all these proteins, the $\mathrm{M}$ protein is the most abundant protein in the virions and forms an outer protein shell around the nucleocapsid, constituting the bridge between the nucleocapsid and viral envelope [4]. Numerous studies have demonstrated that the $\mathrm{M}$ protein of most paramyxoviruses is a nucleocytoplasmic shuttling protein [5]. In addition to participating in the assembly and budding of progeny virions at 
the cell membrane later in infection [6, 7], the M protein is localized in the nucleus early in infection, which may inhibit host cell transcription [5]. Up to now, the detailed functions of $\mathrm{M}$ protein in the nucleus has only been clarified in some NNSV such as human respiratory syncytial virus (HRSV) [8], vesicular stomatitis virus (VSV) $[9,10]$, and $\mathrm{MeV}$ [11], but the precise functions of M's nuclear localization of NDV and other paramyxoviruses remains enigmatic.

Newcastle disease virus, an important member of the paramyxoviruses, is a highly infectious agent of avians that causes substantial economic losses to the poultry industry worldwide [12]. To date, the role of viral F, HN and NP proteins in the replication and pathogenicity of NDV has been extensively studied [13-16], but for the $\mathrm{M}$ protein, researchers have always focused on the role of $M$ protein in the formation of NDV virus-like particles $[6,17-19]$ and the effect of cellular proteins interacting with $\mathrm{M}$ on the replication and pathogenicity of NDV [20-24]. However, there is limited information about the nuclear localization functions of NDV M protein. A previous study has shown that NDV M protein enters the nucleus via a bipartite nuclear localization signal (NLS) independently of other viral proteins [25]. In our recent studies, we demonstrated that importin $\beta 1$ is the nuclear transport receptor of NDV M protein, mediating the nuclear import of $M$ protein by binding its NLS region $\left({ }^{247}\right.$ KKGKKVIFDKIEEKIRR $\left.{ }^{263}\right)$ through the RanGTPdependent pathway [22]. Moreover, we also found that a recombinant NDV with NLS mutation $\left({ }^{247} \mathrm{AAGAAV}\right.$ IFDKIEEKIAA ${ }^{263}$ ) in the $\mathrm{M}$ protein (rSS1GFP-M/NLSm) results in a pathotype change of virulent NDV and attenuated viral replication and pathogenicity in SPF chickens [22]. These results clearly indicate that nuclear localization of $\mathrm{M}$ protein plays important roles in the replication and pathogenicity of NDV.

In the present study, the parental NDV rSS1GFP and the mutant NDV rSS1GFP-M/NLSm harboring M/NLS mutation were used to investigate the potential functions of $\mathrm{M}$ protein in the nucleus. We found that nuclear localization of NDV M protein not only promoted the cytopathogenicity of NDV but also increased viral RNA synthesis and transcription efficiency. Further microarray analysis revealed that nuclear localization of $\mathrm{M}$ protein obviously affected cellular binding, catalytic activity, transcription regulator activity, molecular function regulator and transporter activity. Remarkably, nuclear localization of $\mathrm{M}$ protein might inhibit host cell transcription, represented by numerous up-regulating genes associated with transcriptional repressor activity and down-regulating genes associated with transcriptional activator activity. In addition, the results of quantitative real time polymerase chain reaction (qRT-PCR) were consistent with those of the microarray results. Moreover, siRNA-mediated knockdown of the selected prospero homeobox 1 (PROX1) (up-regulation gene) or aryl hydrocarbon receptor (AHR) (down-regulation gene) significantly decreased or increased the viral RNA synthesis and viral replication. Overall, our findings revealed that nuclear localization of NDV M protein could promote virus replication by affecting viral RNA synthesis and transcription and inhibiting host cell transcription.

\section{Materials and methods \\ Cells, viruses and antibodies}

Chicken embryonic fibroblasts (DF-1) were purchased from the Cell Resource Center of Shanghai Institutes for Biological Sciences of the Chinese Academy of Sciences. BSR-T7/5 cells stably expressing the T7 phage RNA polymerase were a kind gift from Prof. Zhigao Bu (Harbin Veterinary Research Institute, China). DF-1 and were BSR-T7/5 cells were maintained in Dulbecco's modified Eagle's medium (DMEM) supplemented with $10 \%$ fetal bovine serum (FBS) and antibiotics and were cultured at $37{ }^{\circ} \mathrm{C}$ under $5 \% \mathrm{CO}_{2}$. The parental NDV (rSS1GFP) and the mutant NDV harboring NLS mutation in the M protein (rSS1GFP-M/NLSm) were generated in our previous study [22]. The two viruses were plaque purified three times in DF-1 cells and propagated once in specificpathogen-free (SPF) embryonated chicken eggs. Primary antibody mouse anti-Tubulin monoclonal antibody (sc-53646), mouse anti-GAPDH monoclonal antibody (sc-66163), mouse anti-Lamin B1 monoclonal antibody (sc-56143), and mouse anti-GFP monoclonal antibody (sc-9996) were purchased from Santa Cruz Biotechnology (USA). Mouse anti-PROX1 monoclonal antibody (ab33219), and rabbit anti-AHR polyclonal antibody (ab84833) were purchased from Abcam (UK).

\section{Indirect immunofluorescence assay}

DF-1 cells grown in 12-well plates were infected with NDV strain rSS1GFP or rSS1GFP-M/NLSm at a multiplicity of infection (MOI) of 5 and then prepared for immunofluorescence analysis at 6,12 and 18 hours postinfection (hpi). At the indicated time, cells were rinsed with phosphate-buffered saline (PBS), fixed with $4 \%$ paraformaldehyde for $15 \mathrm{~min}$, and then permeabilized with $0.25 \%$ Triton X-100 for 5 min. Cells were rinsed with PBS and blocked with 10\% FBS in PBS for $30 \mathrm{~min}$, and then incubated with mouse anti-M polyclonal antibody [21] diluted in PBS containing 10\% FBS for $1 \mathrm{~h}$. After three washes with PBS, the cells were incubated with Alexa Fluor 488 goat anti-mouse immunoglobulin G antibody (Invitrogen) for $1 \mathrm{~h}$. Cells were counterstained with DAPI (Sigma) to detect the nuclei. Images were captured with a 
fluorescence microscope and processed with Adobe Photoshop 7.0 software.

\section{Syncytia assays}

DF-1 cells were grown to $80 \%$ confluence in 6-well plates and then co-transfected with plasmids pCI-F $(1 \mu \mathrm{g})$, pCIHN $(1 \mu \mathrm{g})$, and pCI-M $(1 \mu \mathrm{g})$ or pCI-M/NLSm $(1 \mu \mathrm{g})$ using FuGENE HD Transfection Reagent (Promega) according to the manufacturer's instructions. Cells cotransfected with pCI-F and pCI-HN were used as controls. After 3 days post-transfection, cells were rinsed with PBS, fixed with cold methanol and then stained with Giemsa. The number of syncytia (cells containing more than three nuclei) was counted in ten random areas of the well.

\section{Minigenome assays}

To evaluate the effect of M's nuclear localization on viral RNA synthesis, the minigenome assays were performed as described previously [26]. Briefly, BSR-T7/5 cells in six-well plates were transfected with pTVT-TGL $(1 \mu \mathrm{g})$, pCI-NP $(1 \mu \mathrm{g})$, pCI-P $(0.5 \mu \mathrm{g})$, pCI-L $(0.5 \mu \mathrm{g})$, pCI-M $(1 \mu \mathrm{g})$ or $\mathrm{pCI}-\mathrm{M} / \mathrm{NLSm}(1 \mu \mathrm{g})$ using FuGENE HD Transfection Reagent. For negative controls, pCI-M or pCI-M/ $\mathrm{NLSm}$ was replaced by empty vector pCI-neo in the minigenome system to normalize the total amount of transfected DNA. To detect minigenome-specific RNA and protein levels, the cells were harvested at 12, 24, 36 and 48 hours post-transfection (hpt) for real-time PCR or Western blotting analysis. All assays were repeated at least three times.

\section{Quantification of minigenomic or viral RNA synthesis by qRT-PCR}

Plasmids-transfected BSR-T7/5 cells or viruses-infected DF-1 cells were collected and then treated with TRIzol reagent (Invitrogen) according to the manufacturer's instructions. Total RNA was extracted and reverse-transcribed (2 $\mu \mathrm{g}$ per sample) as described previously [27]. Quantification of minigenomic RNA synthesis [27] and viral RNA synthesis [16] by qRT-PCR was performed as previously described, respectively. In addition, primers qGFP-F (5'-CGACAAGCAGAAGAACGGCATCA$3^{\prime}$ ) and qGFP-R (5'-GGACTGGGTGCTCAGGTAGTG GTT $-3^{\prime}$ ) were used to quantify the GFP gene. qRT-PCR experiments were performed using SYBR Premix Ex Taq (TaKaRa, Japan) according to the manufacturer's proto$\mathrm{col}$. All the reactions were performed in a $10 \mu \mathrm{L}$ volume containing $5 \mu \mathrm{L}$ of $2 \times$ SYBR Premix Ex Taq, $200 \mathrm{nM}$ of each primer, and $0.2 \mu \mathrm{L}$ ROX reference DyeII. The cycling parameters were 1 cycle at $94{ }^{\circ} \mathrm{C}$ for $30 \mathrm{~s}$, followed by 40 cycles at $94{ }^{\circ} \mathrm{C}$ for $5 \mathrm{~s}, 60{ }^{\circ} \mathrm{C}$ for $10 \mathrm{~s}$, and $60{ }^{\circ} \mathrm{C}$ for $15 \mathrm{~s}$.
The threshold cycle $2^{-\Delta \Delta C T}$ method was used to determine the fold change of gene expression levels.

\section{Cell fractionation and Western blotting}

DF-1 cells infected with rSS1GFP and rSS1GFP-M/NLSm were washed twice with PBS and fractionated for extraction of the nuclear and cytoplasmic proteins following the manufacturer's instructions (Beyotime Biotechnology, China). The nuclear or cytoplasmic proteins were resolved by sodium dodecyl sulfate polyacrylamide gel electrophoresis (SDS-PAGE), and then transferred onto a polyvinylidene difluoride (PVDF) membrane. The membranes were blocked for $1 \mathrm{~h}$ at room temperature with $5 \%$ skim milk in Tris-buffered saline-Tween (TBST) $(20 \mathrm{mM}$ Tris- $\mathrm{HCl}$ [pH 7.4], $137 \mathrm{mM} \mathrm{NaCl}$, and $0.1 \%$ Tween-20) and then incubated overnight at $4{ }^{\circ} \mathrm{C}$ with the primary polyclonal antibody against $\mathrm{M}$. The blots were washed three times in TBST buffer and incubated for $1 \mathrm{~h}$ at room temperature with horseradish peroxidase-conjugated anti-mouse IgG. Mouse anti-Lamin B1 or anti-Tubulin monoclonal antibody was used as an internal standard. The relative levels of the M protein to control Lamin B1 or Tubulin expression were determined by densitometry using Bandscan 5.0 software.

\section{Microarray analysis}

Transcriptional profiles were determined by microarray analysis of nuclear RNA isolated from the nucleus of rSS1GFP- or rSS1GFP-M/NLSm- or mock-infected cells at 6,12 and 18 hpi. Total RNA were extracted from both infected and non-infected DF-1 cells using TRIzol reagent (Invitrogen), and nuclear RNA was further purified by Cytoplasmic and Nuclear RNA Purification Kit (Norgen, Canada) following the manufacturer's protocol. The nuclear RNA was then amplified, labeled and purified using a GeneChip 3' IVT Express Kit (Affymetrix) to obtain biotin-labeled cRNA. Array hybridization and washing were performed using GeneChip ${ }^{\circledR}$ Hybridization and the Wash and Stain Kit (Affymetrix) in the Hybridization Oven 645 (Affymetrix) and Fluidics Station 450 (Affymetrix). Slides were scanned using a GeneChip Scanner 3000 and raw data were normalized using the MAS 5.0 algorithm, Gene Spring Software 11.0 (Annoroad Gene Technology).

$T$-test and significant analysis of microarray were performed to identify the genes that had significantly different expression levels $(P<0.05$ and $>2$-fold change) with infection compared to levels in mock infections. For biofunction and pathway analysis, files containing significantly differentially expressed (SDE) genes were uploaded into IPA platform (Ingenuity Systems, CA, USA). Fisher's exact test was used to determine the probability that each 
biological function assigned to the genes within each data set was due to chance alone.

\section{Analysis of gene expression by qRT-PCR}

Based on the microarray results, 12 genes were selected for the qRT-PCR analysis using SYBR Premix Ex Taq Kit (TaKaRa, Japan) according to the manufacturer's instructions. The sequences of the selected SDE genes were searched in GenBank, and primers (Table 1) for qRTPCR were designed based on the target sequences using Primer Premier 5.0 Software. All the reactions were performed in a $10 \mu \mathrm{L}$ volume containing $5 \mu \mathrm{L}$ of $2 \times$ SYBR Premix Ex Taq, $200 \mathrm{nM}$ of each primer, and $0.2 \mu \mathrm{L}$ ROX reference DyeII. The cycling parameters were 1 cycle at $95{ }^{\circ} \mathrm{C}$ for $5 \mathrm{~s}$ followed by 40 cycles at $95^{\circ} \mathrm{C}$ for $5 \mathrm{~s}$ and $60{ }^{\circ} \mathrm{C}$ for $31 \mathrm{~s}$. One cycle of melting curve analysis was added for all reactions to verify product specificity. The relative levels of gene expression were normalized to that of the GAPDH gene. The threshold cycle $2^{-\triangle \triangle}$ CT method was used to determine the fold change of gene expression levels.

\section{Small interfering RNA (siRNA) assays}

Small interfering RNA-mediated RNA interference was used to knock down ATF6 and AHR in BSR-T7/5 cells. Mouse PROX1 siRNA (sc-152489), AHR siRNA (sc-29655) and Control siRNA (sc-37007) were purchased from Santa Cruz Biotechnology Company. For transfection with the siRNA against PROX1 or AHR, low-passage BSR-T7/5 cells grown in 6-well plates were transfected with 30 pmol siRNA using $9 \mu \mathrm{L}$ Lipofectamine RNAiMAX (Thermo Fisher Scientific, USA) in Opti-MEM medium (Thermo Fisher Scientific).
The knockdown efficiency was measured by examining endogenous protein expression by Western blotting analysis after $48 \mathrm{~h}$ transfection. To study the effect of PROX1 or AHR knockdown on the replication of NDV, the viruses were used to infect PROX1 or AHR siRNAtreated BSR-T7/5 cells at an MOI of 5 . The detection of viral RNA synthesis and viral replication in BSR-T7/5 cells were examined as described above.

\section{Statistical analysis}

Differences in the expression level of genes and virus titers between cells infected with rSS1GFP and rSS1GFP-M/NLSm were analyzed using SPSS Statistics software. The independent-samples $t$ test was used for data analysis. A $P$-value of $<0.05$ was considered significant. $P$-values are indicated by asterisks $\left({ }^{*} P<0.05,{ }^{* *} P<0.01\right.$, *** $P<0.001)$.

\section{Results}

Nuclear localization of $\mathrm{M}$ protein promotes the cytopathogenicity of NDV

We previously reported that NLS mutation in NDV $M$ protein not only disrupted the nuclear localization of $M$ protein, but also impaired the replication efficiency and plaque formation ability of NDV [22]. To learn more about the effect of NLS mutation on the dynamic changes of the subcellular localization of $\mathrm{M}$, we compared the localization of the M protein in rSS1GFP- and rSS1GFP-M/NLSm-infected cells at different time points. The results show that the $\mathrm{M}$ protein of rSS1GFP was primarily localized in the nucleolus followed by a discrete punctuate staining pattern at $6 \mathrm{hpi}$, and then was found in the largest concentration in the nucleus and nucleolus

Table 1 Quantitative real-time PCR primers used in this study

\begin{tabular}{|c|c|c|c|}
\hline Gene name & Forward primer $\left(5^{\prime} \rightarrow 3^{\prime}\right)$ & Reverse primer $\left(5^{\prime} \rightarrow 3^{\prime}\right)$ & GenBank no. \\
\hline NDV M & CTGTGCTTGTGAAGGCGAGAGGT & TGGGGAGAGGCATTTGCTATAGGAT & KP742770 \\
\hline PROX1 & GCAGGTCAGACAACGAGATGTGC & AGGAATTTGGCCCTTGGTCCTTC & NM_001005616 \\
\hline AHRR & TCATCACGAAGGTGCAGCTTTCG & TGCTGTTGGGCAACAACATATTCTG & HQ340610 \\
\hline RARA & AGAGCACCAGCTCAGAGGAGATCGT & ACCCCATAGTGGTACCCGGAGGAT & NM_204536 \\
\hline ZEB2 & CAGCGACACAGCCATTATTTACCCC & AGTTCCAGGTGGCAGGTCGTTTTC & NM_001318466 \\
\hline PAIP2 & AGCCCAAGCATCATCAGTGAAGATG & CСACAACTCСТCTTCAATCTGCCTG & XM_025154840 \\
\hline RUNX2 & ACCACAGAGCCATAAAGGTGACG & GGGACCCCTACTCTCATACTGGGA & NM_204128 \\
\hline $\mathrm{AHR}$ & GCGTAACATGAAGTTGCCCTTCATG & GTTTTGCCTCCTTTTCCTGTGGTG & NM_204118 \\
\hline HOXB4 & GTTCCCACCCTGTGAAGAGTATTCC & TCATGTTGGAAAGTGCTCTCTCGC & NM_205293 \\
\hline NF1A & AACCCGAGGTAAAGCAGAAATGG & GAGGCTTTTTTCCTGTGACTGTGAG & NM_205273 \\
\hline IRF2 & GAGCCAGTTGAATCATCTTTTGGGA & CAAGGTGCGGCTGTCCTACAACTA & NM_205196 \\
\hline TAF9 & TGATGGCGCAGATCCTGAAGGATA & GTAAATCTTCGCGTCCTCCAGGATG & NM_001277796 \\
\hline LHX2 & GGAGATTTTCGGTGCAGAGATGTGC & GTGGTCAGCATCTTGTTGCAAGTGG & NM_204889 \\
\hline GAPDH & TCAAGGCTGAGAACGGGAAACTTG & TGGACTCCACAACATACTCAGCACC & NM_204305 \\
\hline
\end{tabular}


at $12 \mathrm{hpi}$; whereas the M protein was distributed diffusely in the cytoplasm, with some still localized in the nucleolus at 18 hpi (Figure 1A). By contrast, the $M$ protein of rSS1GFP-M/NLSm accumulated around the nucleus at $6 \mathrm{hpi}$, and then distributed exclusively in the cytoplasm at 12 and 18 hpi (Figure 1A). In addition, the intracellular localization of rSS1GFP and rSS1GFP-M/NLSm $\mathrm{M}$ protein detected by Western blotting was consistent with the immunofluorescence analysis (Figure 1B). Next, the cytopathic effect (CPE) and the expression of green fluorescent protein (GFP) in virus-infected cells were evaluated. We found that the CPE and GFP expression in rSS1GFP-infected cells started early at $6 \mathrm{hpi}$ and the extensive CPE and GFP expression appeared at $18 \mathrm{hpi}$, and then the cell monolayer was absolutely destroyed at 36 hpi (Figure 1C). However, the slight CPE and GFP expression in rSS1GFP-M/NLSm infected cells started at $12 \mathrm{hpi}$ and the cell monolayer was still existent at

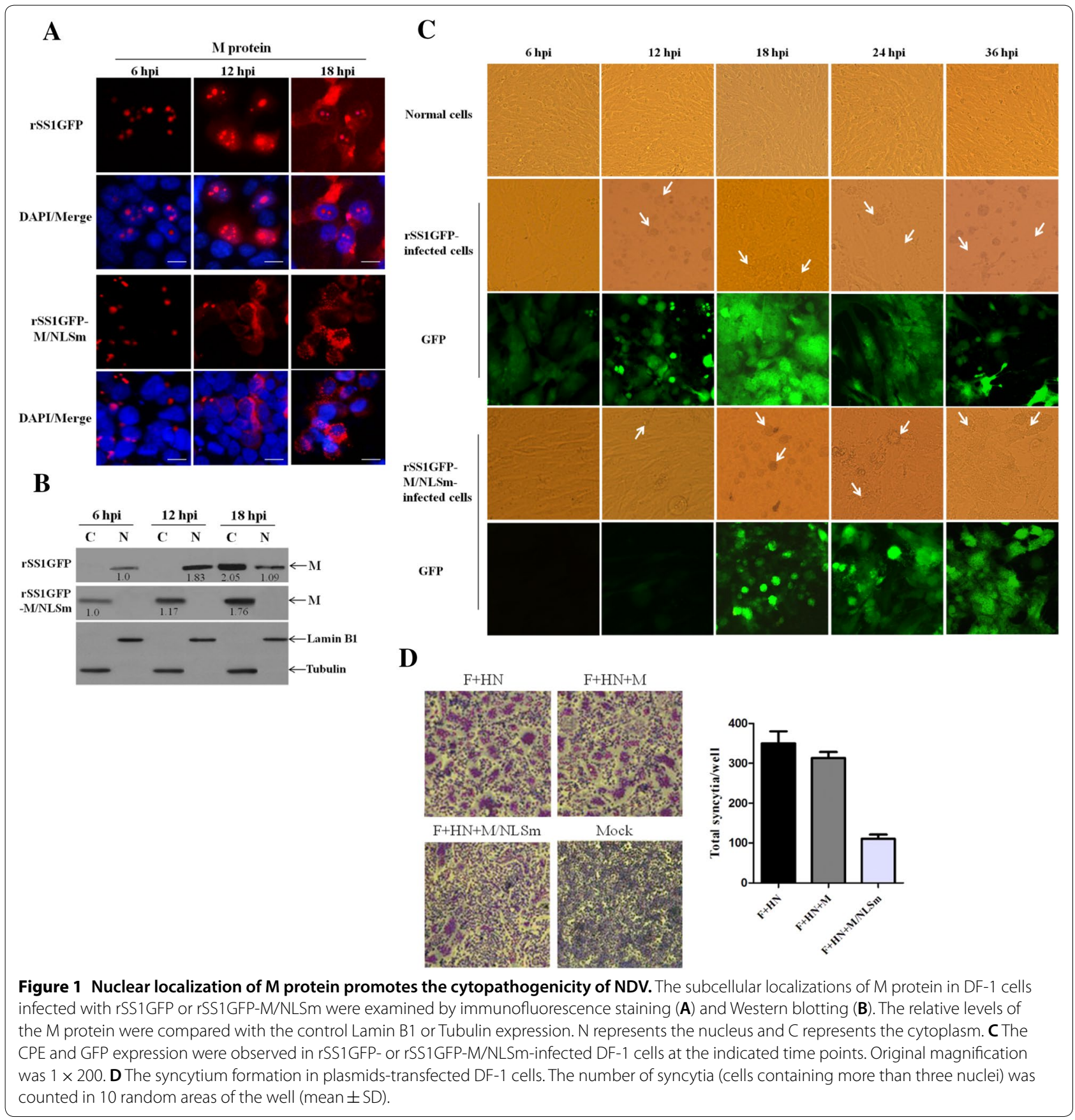


36 hpi (Figure 1C), demonstrating that rSS1GFP-M/ NLSm induced much slighter CPE and GFP expression than that of rSS1GFP. Meanwhile, the syncytia assays show that co-expression of F, HN and M/NLSm caused a marked reduction in cell-cell fusion when compared to co-expression of $\mathrm{F}$ and $\mathrm{HN}$ or F, HN and M (Figure 1D), indicating that M's cytoplasmic localization affected the amount of cell-cell fusion. Therefore, these results confirm that nuclear localization of $\mathrm{M}$ protein could promote the cytopathogenicity of NDV.

\section{Nuclear localization of M protein affects viral RNA synthesis and transcription}

To investigate the role of M's nuclear localization in viral RNA synthesis and transcription, an NDV minigenome assay was first performed using GFP as a reporter gene (Additional file 1). The expression of GFP genomic RNA, antigenomic RNA and mRNA was quantified by qRTPCR to represent the viral RNA synthesis and transcription. The results show that the relative expression level of GFP genomic RNA was decreased in the presence of $\mathrm{M} / \mathrm{NLSm}$ at different time points in comparison to the presence of $M$ (Figure 2A). Although the relative GFP antigenomic RNA had no significant change at $12 \mathrm{hpt}$, it shows obviously reduced expression levels in the subsequent time points (Figure 2B). Consistent with the relative expression levels of GFP genomic RNA, the relative GFP mRNA levels significantly declined in the presence of M/NLSm, especially at $36 \mathrm{hpt}$ and $48 \mathrm{hpt}(P<0.001)$ (Figure $2 \mathrm{C}$ ). Moreover, Western blotting analysis also shows that the GFP expression levels in M/NLSm-cell lysates were much lower than that in M-cell lysates at $36 \mathrm{hpt}$ and $48 \mathrm{hpt}$ (Figure 2D).

To further verify whether the disruption of M's nuclear localization will affect viral RNA synthesis and transcription, we analyzed the RNA levels of NP and P genes and the mRNA levels of $M$ and GFP genes in rSS1GFP- and rSS1GFP-M/NLSm-infected cells. As shown in Figure $3 \mathrm{~A}$, there were statistically significant differences in the relative RNA levels (corresponding to the NP and
A

Genomic-sense RNA from antigenomic-sense RNA

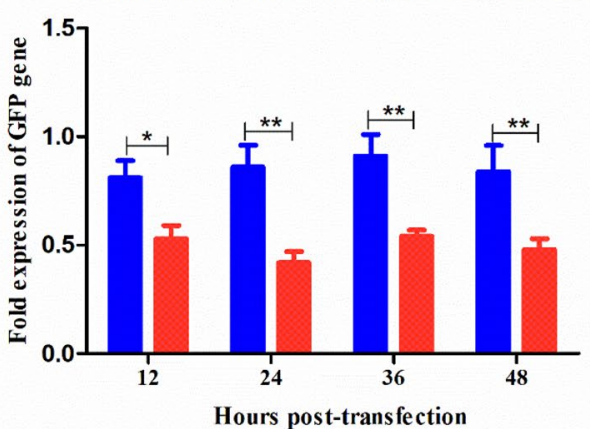

C

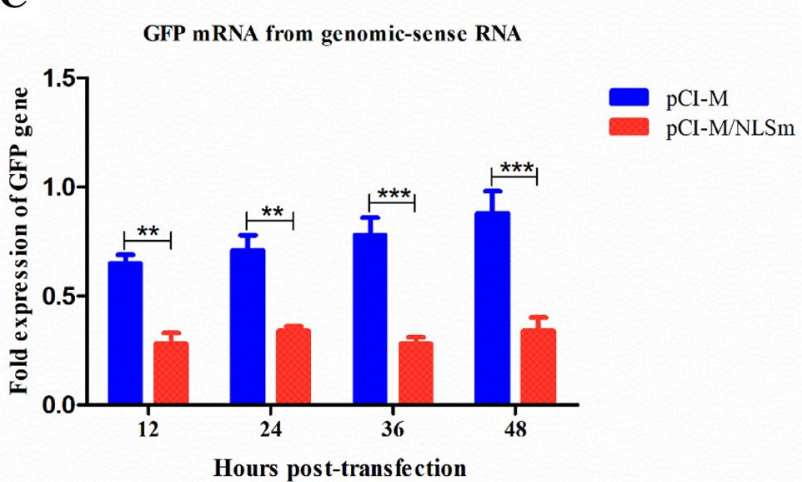

B

Antigenomic-sense RNA from nimigenome and genomic-sense RNA

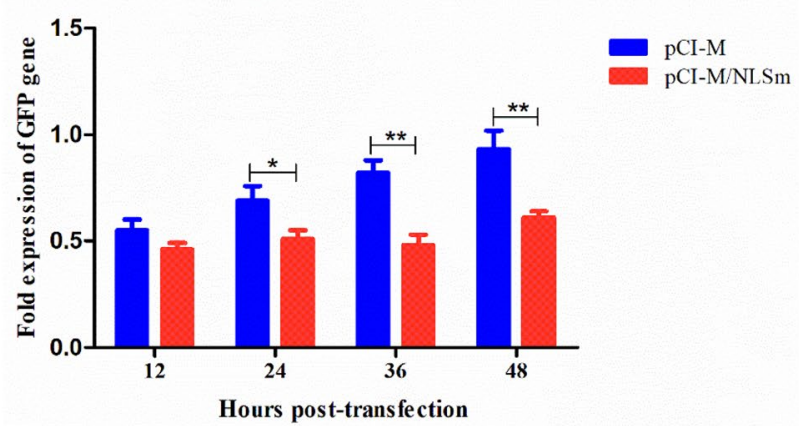

D

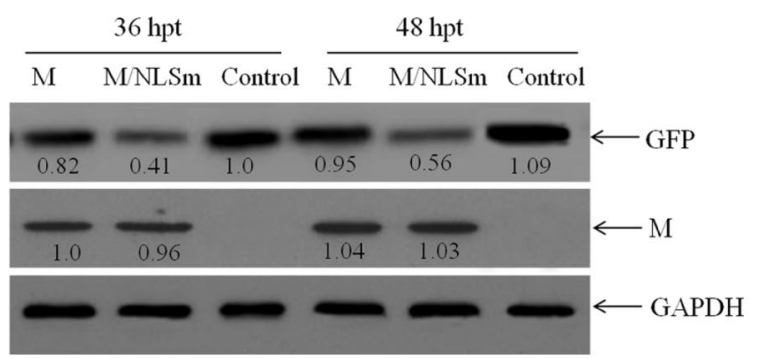

Figure 2 Quantitative analysis of genomic RNA, antigenomic RNA, mRNA and protein in a minigenomic assay. Relative fold expression of genomic RNA (A), antigenomic RNA (B), and mRNA $(\mathbf{C})$ in the minigenome system caused by M or M/NLSm were measured by qRT-PCR. Error bars represent standard deviations (mean $\pm \mathrm{SD})\left({ }^{*} P<0.05 ;{ }^{* *} P<0.01 ;{ }^{* * *} P<0.001\right.$ compared to the value of negative control). $\mathbf{D}$ Expression of GFP in the minigenome system caused by M or M/NLSm was detected by Western blotting at 36 and 48 hpt. The relative levels of the M and GFP proteins were compared with the control GAPDH expression. 

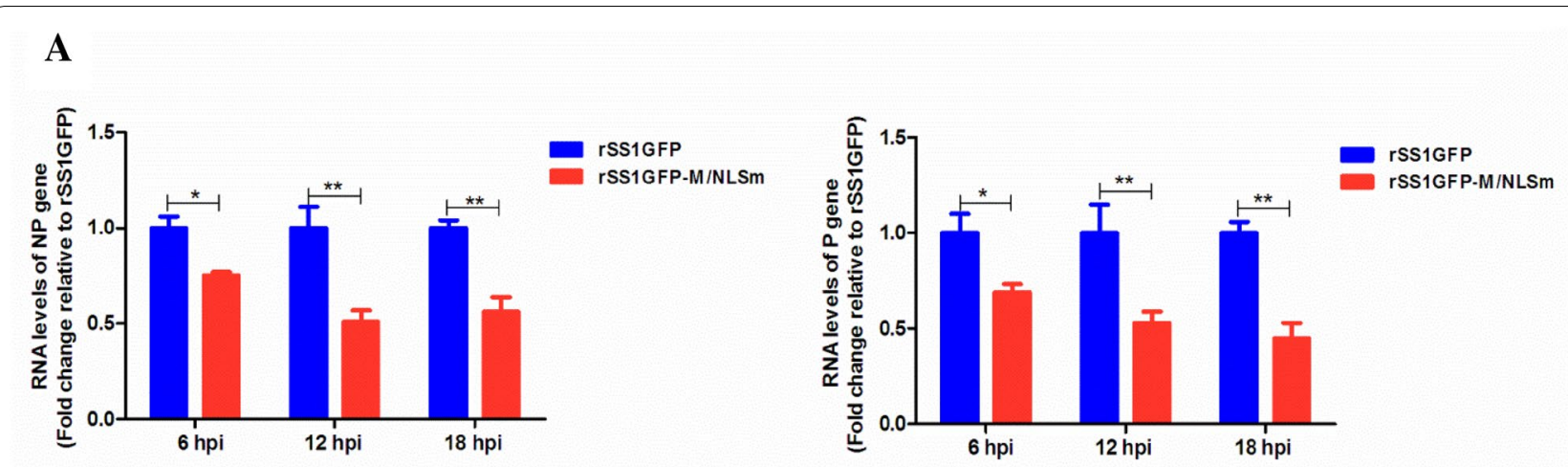

B
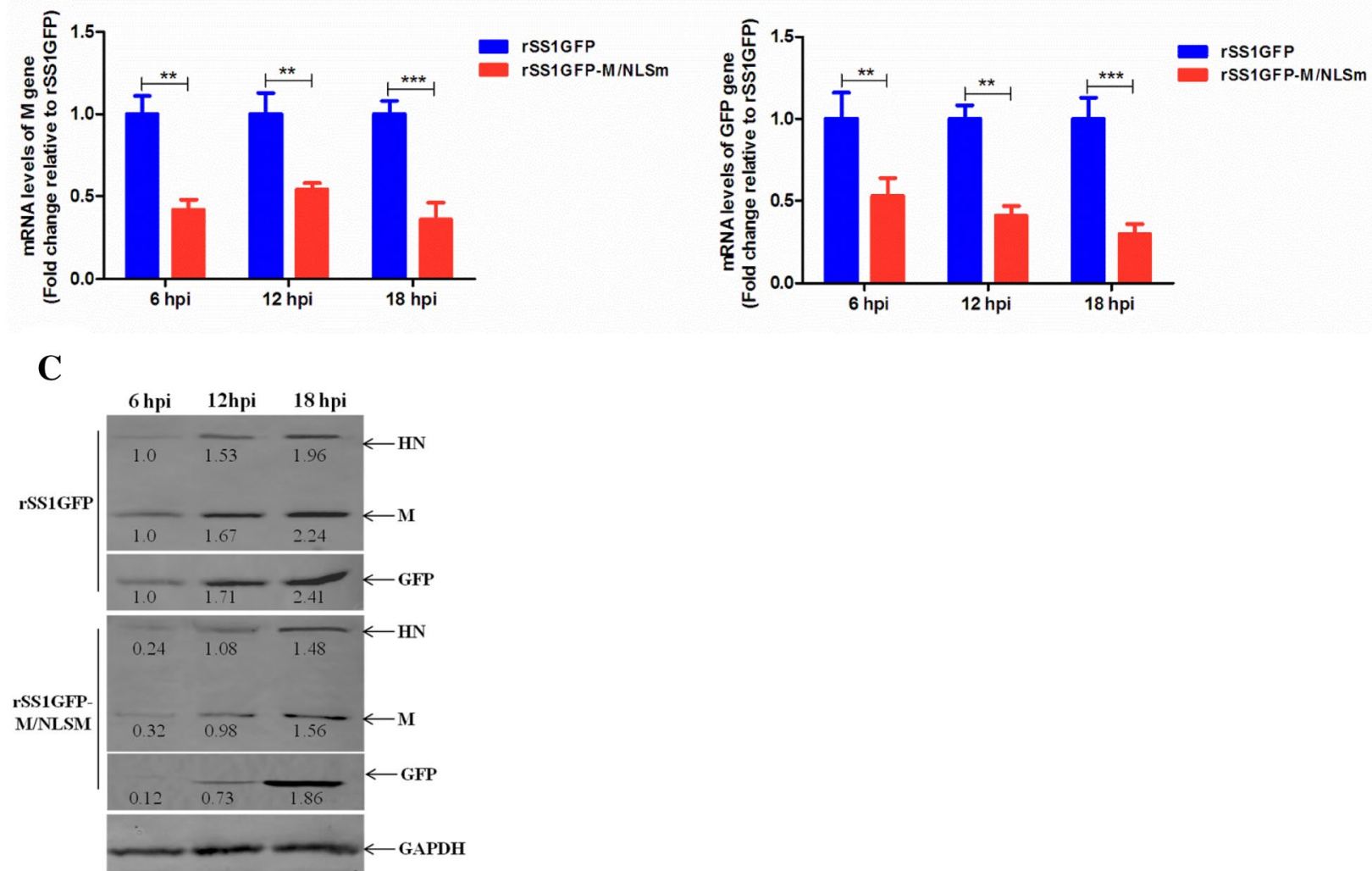

Figure 3 Comparison of the viral RNA synthesis and transcription in DF-1 cells. A The viral RNA synthesis corresponding to the NP and $P$ genes and $\mathbf{B}$ viral transcription corresponding to the $M$ and GFP genes in rSS1GFP- and rSS1GFP-M/NLSm-infected cells were detected by qRT-PCR. Error bars represent standard deviations (mean \pm SD) $\left({ }^{*} P<0.05 ;{ }^{* *} P<0.01 ;{ }^{* *} P<0.001\right.$ compared to the value of rSS1GFP-M/NLSm). C The expression levels of M, HN and GFP proteins in rSS1GFP- and rSS1GFP-M/NLSm-infected cells were examined by Western blotting. The relative levels of the $\mathrm{M}, \mathrm{HN}$ and GFP proteins were compared with the control GAPDH expression.

$P$ genes) between cells infected with rSS1GFP and rSS1 GFP-M/NLSm at 6 hpi $(P<0.05)$. Moreover, the relative levels of viral RNA in rSS1GFP-M/NLSm-infected cells were more decreased than that in rSS1GFP-infected cells at 12 and 18 hpi $(P<0.01)$ (Figure $3 \mathrm{~A})$. On the contrary, we found that the relative mRNA levels of $\mathrm{M}$ and GFP genes in rSS1GFP-M/NLSm-infected cells were also much lower than that in rSS1GFP-infected cells at 6 and 12 hpi $(P<0.01)$, and significantly lower at $18 \mathrm{hpi}$ $(P<0.001)$ (Figure 3B). Meanwhile, the expression levels of $\mathrm{HN}, \mathrm{M}$ and GFP proteins were relatively decreased during the course of rSS1GFP-M/NLSm infection (Figure $3 C$ ), suggesting that cytoplasmic $M$ protein could result in the reduced viral transcription. Collectively, 
these results indicate that nuclear localization of $M$ protein affected the viral RNA synthesis and transcription, which would benefit NDV replication.

\section{Nuclear localization of $M$ protein induces robust host response by microarray analysis}

To understand the contribution of M's nuclear localization to NDV replication, we compared transcriptional profiles of host genes in DF-1 cells infected with
rSS1GFP or rSS1GFP-M/NLSm by microarray analysis. A total of 50, 368 and 1097 genes were obtained with significantly differential expression (SDE) levels $(P<0.05$ and $>2$-fold change $)$ during rSS1GFP infection at 6, 12 and $18 \mathrm{hpi}$, respectively, whereas the corresponding gene numbers were 12, 95 and 395 for rSS1GFP-M/NLSm at the indicated time points (Figure 4A). In addition, a Venn diagram summarizing the distribution of SDE genes revealed that only 26 and 102
A

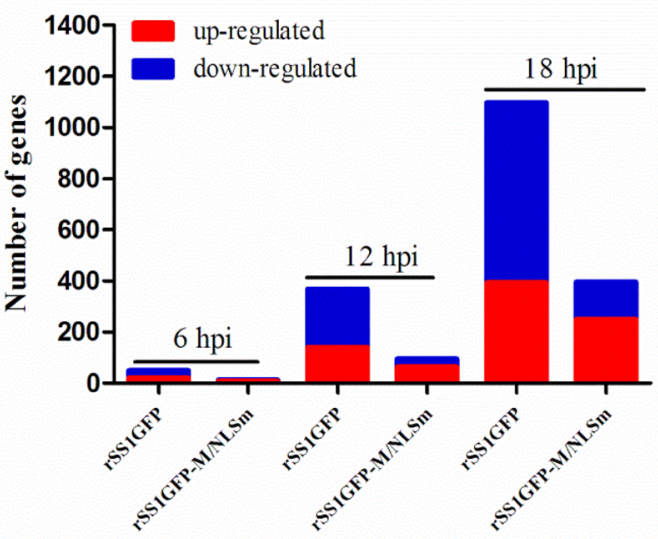

C
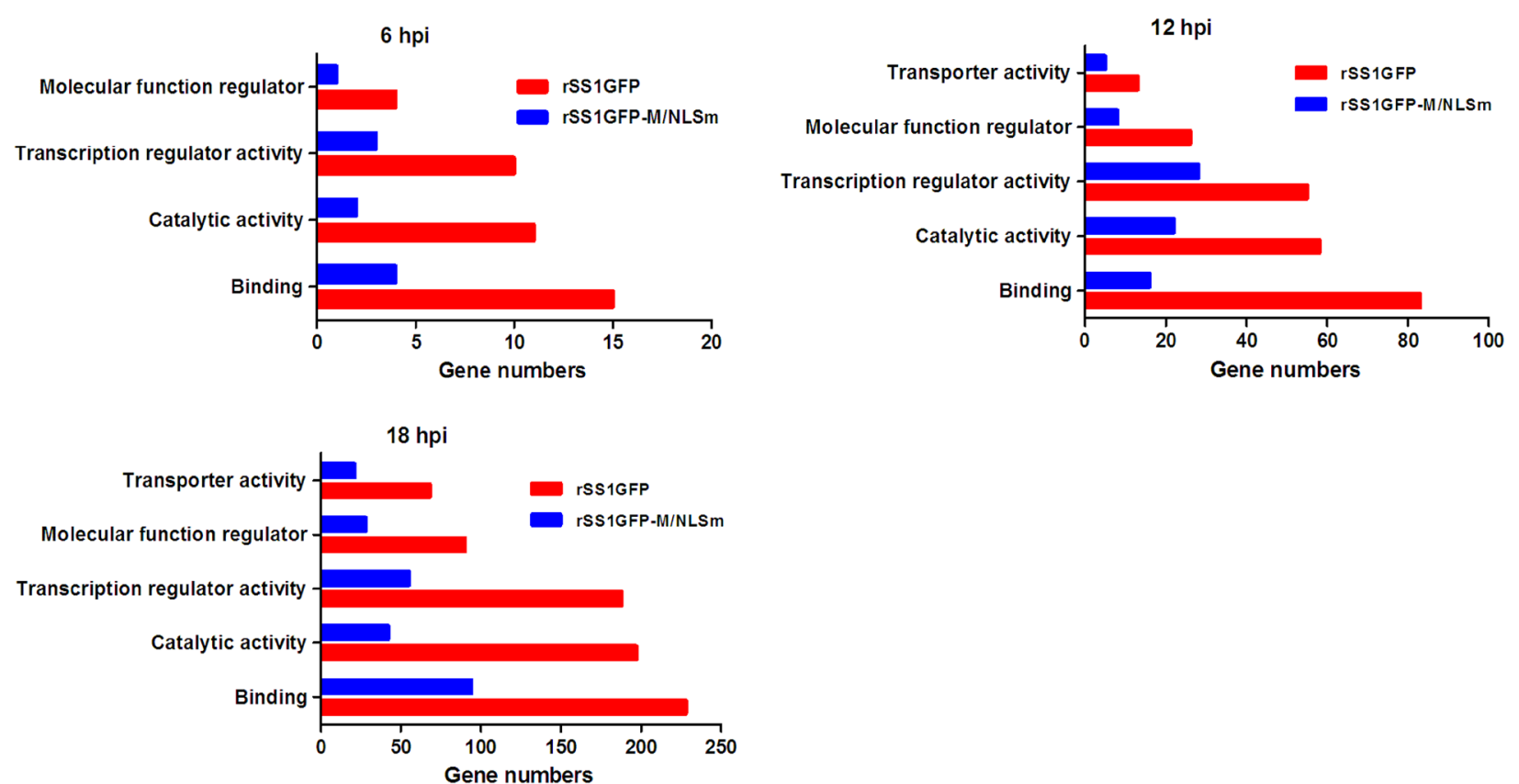

Figure 4 Microarray analysis of gene expression in DF-1 cells infected with rSS1GFP and rSS1GFP-M/NLSm. A Numbers of different expressed genes during infection with rSS1GFP or rSS1GFP-M/NLSm virus relative to mock infection at 6,12 and $18 \mathrm{hpi}(P<0.05$, fold change $>2)$. B Venn diagram showing the distribution of different expressed genes during infection with rSS1GFP or rSS1GFP-M/NLSm virus at 12 and 18 hpi. C Functional categories of different expressed genes in cells infected with rSS1GFP or rSS1GFP-M/NLSm virus at 6, 12 and 18 hpi. 
genes were shared by rSS1GFP and rSS1GFP-M/NLSm at $12 \mathrm{hpi}$ and $18 \mathrm{hpi}$, respectively (Figure 4B). Biological function analysis using Ingenuity Pathway Analysis (IPA) platform demonstrates that the remarkable differences in gene expression between rSS1GFP and rSS1GFP-M/NLSm were mainly associated with binding, catalytic activity, transcription regulator activity, molecular function regulator and transporter activity (Figure 4C). Canonical pathway analysis shows that rSS1GFP preferred to modulate the signaling pathways associated with virus infection, while rSS1GFP$\mathrm{M} / \mathrm{NLSm}$ tended to regulate metabolism pathways related to cellular function and maintenance (Table 2). Together, these results indicate that rSS1GFP elicited a more potent host response than rSS1GFP-M/NLSm.

\section{Nuclear localization of $M$ protein inhibits host cell transcription}

Several studies have demonstrated that the $M$ protein of NNSV including HRSV, VSV and MeV can inhibit host cell transcription in various ways [8-11, 28-30]. To determine whether the NDV M protein has the ability to inhibit host cell transcription, we mainly focused on the expression profiles of transcription regulator activity-related genes in the results of microarray analysis. A total of 233 and 86 SDE genes associated with transcription regulator activity were identified in DF-1 cells infected with rSS1GFP and rSS1GFP-M/NLSm (Figure $5 \mathrm{~A}$ ), respectively. Meanwhile, the number of SDE genes in rSS1GFP-infected cells mainly showed a tendency of down-regulation (Figure 5A). However, only one common gene was found at 6,12 and 18 hpi in the virus-infected cells using a Venn diagram (Figure 5B).

Table 2 Top five IPA canonical pathways modulated by rSS1GFP and rSS1GFP-M/NLSm

\begin{tabular}{|c|c|c|c|c|}
\hline Time points (hpi) & Virus & IPA canonical pathway ${ }^{a}$ & $P$ value & Gene count $^{\mathbf{b}}$ \\
\hline \multirow[t]{8}{*}{6} & \multirow[t]{5}{*}{ rSS1GFP } & Toll-like receptor signaling pathway & $3.62 \mathrm{E}-04$ & $3 / 10$ \\
\hline & & RIG-I-like receptor signaling pathway & $4.15 \mathrm{E}-04$ & $1 / 8$ \\
\hline & & NF-kappa B signaling pathway & $2.18 \mathrm{E}-03$ & $2 / 8$ \\
\hline & & Hepatitis C & $3.70 E-03$ & $2 / 12$ \\
\hline & & TGF- $\beta$ signaling pathway & $4.53 \mathrm{E}-03$ & $1 / 6$ \\
\hline & \multirow[t]{3}{*}{ rSS1GFP-M/NLSm } & Apelin signaling pathway & $2.15 E-03$ & $0 / 2$ \\
\hline & & Hippo signaling pathway & $3.44 \mathrm{E}-03$ & $1 / 5$ \\
\hline & & Pyrimidine metabolism & $1.35 \mathrm{E}-02$ & $0 / 3$ \\
\hline \multirow[t]{10}{*}{12} & \multirow[t]{5}{*}{ rSS1GFP } & Cytokine-cytokine receptor interaction & $8.93 \mathrm{E}-10$ & $8 / 12$ \\
\hline & & HTLV-1 infection & $2.06 \mathrm{E}-9$ & $9 / 21$ \\
\hline & & Kaposi sarcoma-associated herpesvirus infection & $6.38 \mathrm{E}-9$ & $10 / 32$ \\
\hline & & Transcriptional misregulation in cancer & $2.28 \mathrm{E}-8$ & $4 / 7$ \\
\hline & & TNF signaling pathway & $3.80 \mathrm{E}-7$ & $6 / 16$ \\
\hline & \multirow[t]{5}{*}{ rSS1GFP-M/NLSm } & Thyroid hormone signaling pathway & $3.63 \mathrm{E}-5$ & $3 / 13$ \\
\hline & & Biosynthesis of amino acids & $4.96 \mathrm{E}-5$ & $1 / 8$ \\
\hline & & Rap1 signaling pathway & $2.11 \mathrm{E}-4$ & $3 / 8$ \\
\hline & & Glycine, serine and threonine metabolism & $2.25 E-3$ & $2 / 10$ \\
\hline & & Non-small cell lung cancer & $2.63 \mathrm{E}-3$ & $1 / 9$ \\
\hline \multirow[t]{10}{*}{18} & \multirow[t]{5}{*}{ rSS1GFP } & MAPK signaling pathway & $1.01 \mathrm{E}-11$ & $21 / 42$ \\
\hline & & TNF signaling pathway & $2.70 E-10$ & $12 / 36$ \\
\hline & & MAPK signaling pathway & $6.99 \mathrm{E}-9$ & $9 / 23$ \\
\hline & & Human papillomavirus infection & $1.38 \mathrm{E}-8$ & $10 / 21$ \\
\hline & & Transcriptional misregulation in cancer & $3.31 \mathrm{E}-8$ & $15 / 38$ \\
\hline & \multirow[t]{5}{*}{ rSS1GFP-M/NLSm } & DNA replication & $1.09 \mathrm{E}-4$ & $6 / 44$ \\
\hline & & Neurotrophin signaling pathway & $1.51 \mathrm{E}-3$ & $4 / 23$ \\
\hline & & Cellular senescence & $2.36 \mathrm{E}-3$ & $3 / 26$ \\
\hline & & Insulin resistance & $4.15 \mathrm{E}-2$ & $2 / 15$ \\
\hline & & Caffeine metabolism & $7.38 \mathrm{E}-2$ & $2 / 12$ \\
\hline
\end{tabular}

a Top 5 IPA significant canonical pathways are represented (cutoff for significance, $P<0.05$ ). Only three pathways were detected in rSS1GFP-M/NLSm-infected cells at 6 hpi.

b Numbers of genes are provided as $X / Y$, where $Y$ is the total number of genes in the pathway and $X$ is the amount of differentially expressed genes in response to viral infection. 
A

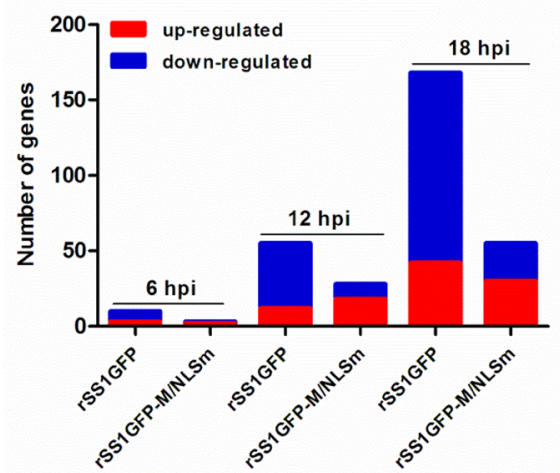

Transcription regulator activity
B

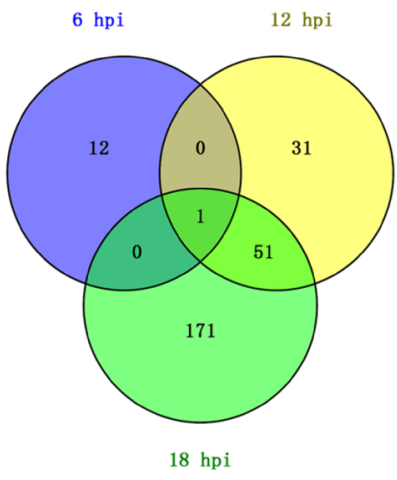

C

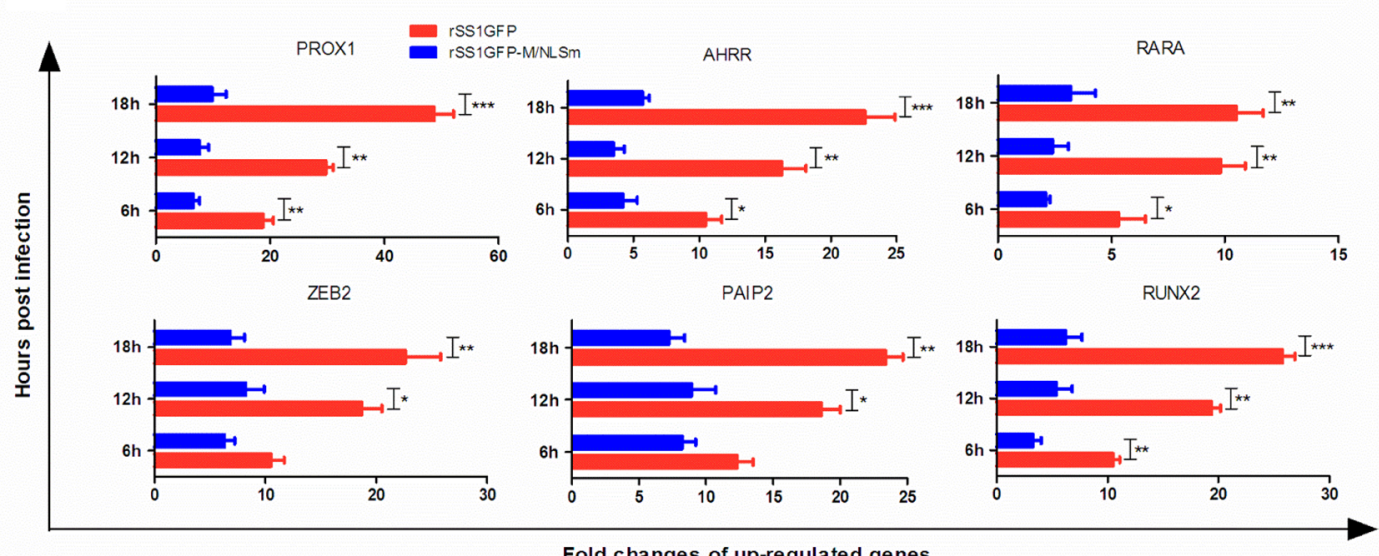

Fold changes of up-regulated genes

D

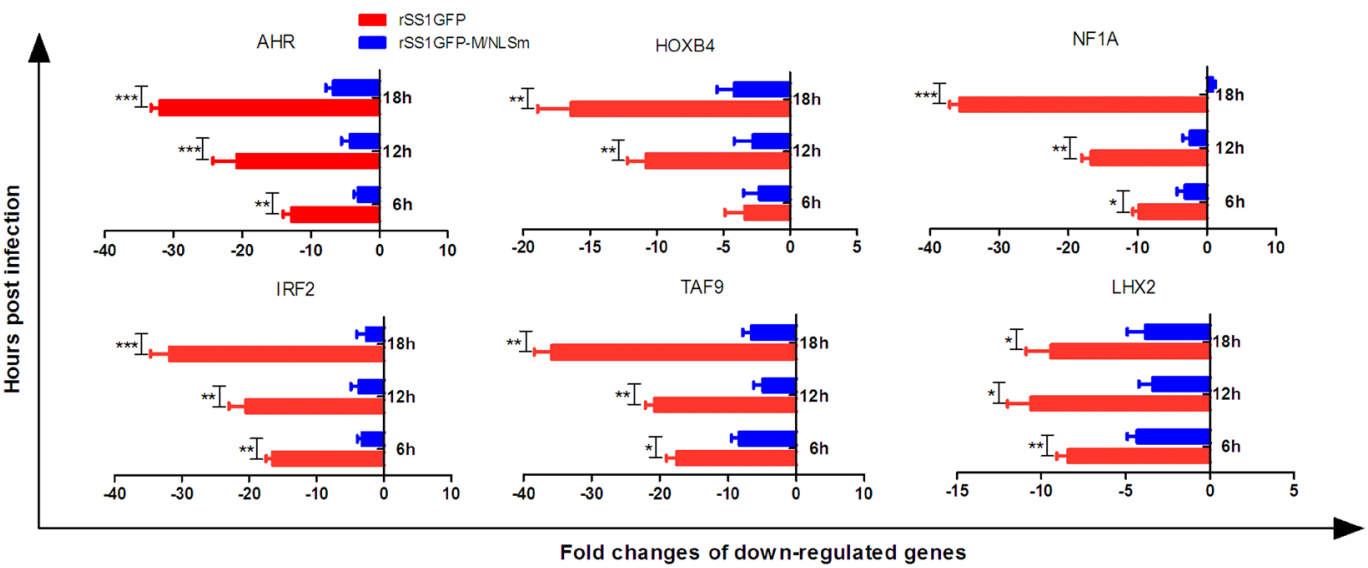

Figure 5 Analysis of the expression levels of transcription regulator activity related genes in DF-1 cells. A Numbers of different expressed genes associated with transcription regulator activity during infection with rSS1GFP or rSS1GFP-M/NLSm virus relative to mock infection at 6, 12 and 18 hpi $(P<0.05$, fold change $>2)$. B Venn diagram showing the distribution of different expressed genes associated with transcription regulator activity during infection with rSS1GFP or rSS1GFP-M/NLSm virus at 6, 12 and 18 hpi. The expression levels of six selected up-regulated genes (C) and six down-regulated genes (D) associated with transcription regulator activity were verified by qRT-PCR. Error bars represent standard deviations (mean $\pm \mathrm{SD})\left({ }^{*} P<0.05 ;{ }^{*} P<0.01 ;{ }^{* *} P<0.001\right.$ compared to the value of $\left.r S S 1 G F P-M / N L S m\right)$. 
Table 3 Top 5 up-regulated SDE genes associated with the transcription regulator activity in virus-infected cells

\begin{tabular}{|c|c|c|c|c|c|c|c|}
\hline \multirow[t]{2}{*}{ Time (hpi) } & \multirow[t]{2}{*}{ Gene symbol } & \multirow[t]{2}{*}{ Gene description } & \multicolumn{2}{|c|}{ rSS1GFP } & \multicolumn{2}{|c|}{$\begin{array}{l}\text { rSS1GFP-M/ } \\
\text { NLSm }\end{array}$} & \multirow[t]{2}{*}{ Molecular function } \\
\hline & & & $\mathrm{FC}^{\mathrm{a}}$ & $P$ value & FC & $P$ value & \\
\hline \multirow[t]{3}{*}{6} & ZEB2 & Zinc finger E-box binding homeobox 2 & 6.5 & $1.21 \mathrm{E}-05$ & 1.2 & $2.30 \mathrm{E}-02$ & Transcriptional repressor activity \\
\hline & RARA & Retinoic acid receptor alpha & 5.3 & $6.40 E-06$ & 0.8 & $1.12 \mathrm{E}-03$ & Transcription corepressor activity \\
\hline & PROX1 & Prospero homeobox 1 & 3.2 & $4.00 \mathrm{E}-04$ & 0.4 & $1.51 \mathrm{E}-02$ & Negative regulation of transcription \\
\hline \multirow[t]{5}{*}{12} & AHRR & Aryl hydrocarbon receptor repressor & 10.2 & $4.21 \mathrm{E}-08$ & 2.3 & $3.32 \mathrm{E}-03$ & Protein heterodimerization activity \\
\hline & ETS2 & ETS proto-oncogene 2 & 8.4 & $3.82 \mathrm{E}-07$ & 1.4 & $2.12 \mathrm{E}-02$ & Transcription repressor activity \\
\hline & KLF11 & Kruppel like factor 11 & 7.6 & $1.09 \mathrm{E}-07$ & 3.6 & $5.16 \mathrm{E}-04$ & Negative regulation of transcription \\
\hline & HDAC9 & Histone deacetylase 9 & 7.1 & 2.67E-06 & 2.7 & 4.11E-02 & Transcription corepressor activity \\
\hline & SAMD4A & Sterile alpha motif domain containing $4 \mathrm{~A}$ & 5.8 & $3.23 \mathrm{E}-06$ & 0.6 & 1.15E-02 & Transcription repressor activity \\
\hline \multirow[t]{5}{*}{18} & PROX1 & Prospero homeobox 1 & 9.6 & $4.12 \mathrm{E}-07$ & 2.2 & $5.43 \mathrm{E}-03$ & Negative regulation of transcription \\
\hline & PAIP2 & Poly $(A)$ binding protein interacting protein 2 & 8.3 & $2.54 \mathrm{E}-05$ & 1.8 & $2.80 \mathrm{E}-02$ & Transcription repressor activity \\
\hline & ETV3 & ETS variant 3 & 6.4 & $3.81 \mathrm{E}-06$ & 3.1 & $4.78 \mathrm{E}-04$ & Repressing transcription factor binding \\
\hline & RUNX2 & Runt related transcription factor 2 & 6.2 & $2.41 \mathrm{E}-03$ & 1.4 & $3.05 E-03$ & Transcription corepressor activity \\
\hline & CCAR1 & Cell division cycle and apoptosis regulator 1 & 5.8 & $1.22 \mathrm{E}-04$ & 2.0 & $1.63 \mathrm{E}-02$ & Transcription corepressor activity \\
\hline
\end{tabular}

a FC: fold change in expression levels relative to those of uninfected cells. Only three SDE genes were found in rSS1GFP -infected cells at 6 hpi.

Table 4 Top 5 down-regulated SDE genes associated with the transcription regulator activity in virus-infected cells

\begin{tabular}{|c|c|c|c|c|c|c|c|}
\hline \multirow[t]{2}{*}{ Time (hpi) } & \multirow[t]{2}{*}{ Gene symbol } & \multirow[t]{2}{*}{ Gene description } & \multicolumn{2}{|c|}{ rSS1GFP } & \multicolumn{2}{|c|}{$\begin{array}{l}\text { rSS1GFP-M/ } \\
\text { NLSm }\end{array}$} & \multirow[t]{2}{*}{ Molecular function } \\
\hline & & & $\mathrm{FC}^{\mathrm{a}}$ & $P$ value & $\mathrm{FC}$ & $P$ value & \\
\hline \multirow[t]{5}{*}{6} & AHR & aryl hydrocarbon receptor & -4.1 & $2.29 \mathrm{E}-05$ & -1.1 & $8.39 \mathrm{E}-04$ & DNA binding transcription factor activity \\
\hline & NF1A & Nuclear factor I A & -3.5 & $2.04 \mathrm{E}-04$ & -0.8 & $2.43 \mathrm{E}-03$ & $\begin{array}{l}\text { RNA polymerase II transcription factor } \\
\text { activity }\end{array}$ \\
\hline & TFCP2L1 & Transcription factor CP2 like 1 & -3.0 & $3.27 \mathrm{E}-06$ & -0.4 & $1.66 \mathrm{E}-02$ & $\begin{array}{l}\text { RNA polymerase II regulatory region } \\
\text { sequence-specific DNA binding }\end{array}$ \\
\hline & SMAD3 & SMAD family member 3 & -2.6 & $2.17 \mathrm{E}-03$ & -0.1 & $2.33 \mathrm{E}-03$ & $\begin{array}{l}\text { RNA polymerase II activating transcrip- } \\
\text { tion factor binding }\end{array}$ \\
\hline & ATXN7L3 & Ataxin 7 like 3 & -2.1 & $1.53 \mathrm{E}-02$ & -0.3 & $1.14 \mathrm{E}-02$ & Transcription activator activity \\
\hline \multirow[t]{5}{*}{12} & IRF2 & Interferon regulatory factor 2 & -8.7 & $2.87 \mathrm{E}-07$ & -1.2 & $1.57 \mathrm{E}-02$ & Transcriptional activator activity \\
\hline & AHR & Aryl hydrocarbon receptor & -7.6 & $3.08 \mathrm{E}-06$ & -1.8 & $3.30 \mathrm{E}-03$ & DNA binding transcription factor activity \\
\hline & TAF9 & $\begin{array}{l}\text { TATA-box binding protein associated } \\
\text { factor } 9\end{array}$ & -6.5 & 1.36E-06 & -2.0 & $3.98 \mathrm{E}-04$ & $\begin{array}{l}\text { RNA polymerase II core promoter } \\
\text { sequence-specific binding }\end{array}$ \\
\hline & ATOH8 & Atonal bHLH transcription factor 8 & -5.8 & $3.11 \mathrm{E}-05$ & -1.3 & $3.54 \mathrm{E}-02$ & Transcription factor binding \\
\hline & CARF & Calcium responsive transcription factor & -4.6 & $1.23 \mathrm{E}-04$ & -2.1 & $1.71 \mathrm{E}-02$ & Transcriptional activator activity \\
\hline \multirow[t]{5}{*}{18} & HOXB4 & homeobox B4 & -10.4 & $5.88 \mathrm{E}-08$ & -2.4 & $2.58 \mathrm{E}-02$ & DNA binding transcription factor activity \\
\hline & AHR & Aryl hydrocarbon receptor & -9.2 & $4.11 \mathrm{E}-07$ & -1.5 & $1.62 \mathrm{E}-03$ & DNA binding transcription factor activity \\
\hline & LHX2 & LIM homeobox 2 & -7.9 & 4.27E-07 & -2.7 & $2.89 \mathrm{E}-04$ & Transcription factor activity \\
\hline & TBX3 & T-box 3 & -6.5 & $5.68 \mathrm{E}-06$ & -1.4 & $3.26 \mathrm{E}-03$ & $\begin{array}{l}\text { RNA polymerase II activating transcrip- } \\
\text { tion factor binding }\end{array}$ \\
\hline & LMO2 & LIM domain only 2 & -5.7 & $1.35 \mathrm{E}-06$ & -0.8 & $1.25 \mathrm{E}-02$ & $\begin{array}{l}\text { RNA polymerase II transcription factor } \\
\text { activity }\end{array}$ \\
\hline
\end{tabular}

${ }^{a}$ FC: fold change in expression levels relative to those of uninfected cells.

A further analysis of the top 5 up-regulated and downregulated SDE genes in rSS1GFP-infected cells shows that the up-regulated SDE genes were mostly associated with the function of transcription repressor activity and negative regulation of transcription (Table 3), while the down-regulated SDE genes were mainly involved in DNA binding or RNA polymerase II transcription factor activity and transcriptional activator activity (Table 4). 
To validate the microarray results, qRT-PCR was performed to examine the expression levels of the 12 selected genes. The results show that the mRNA expression levels of six selected up-regulated genes in rSS1GFPinfected cells were much higher than that in rSS1GFP-M/ NLSm-infected cells, and most gene expression levels were continuously increased from 6 to $18 \mathrm{hpi}$ (Figure $5 \mathrm{C}$ ). By contrast, the mRNA expression levels of six selected down-regulated genes in rSS1GFP-infected cells were relatively lower than that in rSS1GFP-M/NLSminfected cells (Figure 5D). The corresponding changes were consistent with the microarray results. Taken together, we speculated that nuclear localization of NDV $M$ protein inhibited host cell transcription by regulating the expression levels of cellular transcription regulator activity-related genes, which might be responsible for the differences in viral RNA synthesis and viral replication.

\section{Knockdown of PROX1 reduces viral RNA synthesis and viral replication}

PROX1 is reported to be a homeodomain transcription factor essential for the development of a variety of organs, including the lymphatic system [31], the liver [32], the brain [33], and the heart [34]. In addition, a previous study has demonstrated that Kaposi's sarcoma herpes virus (KSHV) latent gene Kaposin-B can enhance the mRNA stability of PROX1 gene and cause the upregulation of PROX1, which is essential for KSHV replication [35]. The results of microarray analysis and qRT-PCR show that rSS1GFP infection resulted in the relatively high expression level of PROX1. Therefore, the role of PROX1 in the RNA synthesis and replication of NDV was investigated. We found that the expression levels of PROX1 protein was increased either in rSS1GFPinfected or in pCI-M-transfected BSR-T7/5 cells when compared to that of PROX1 in rSS1GFP-M/NLSminfected or pCI-M/NLSm-transfected cells or normal cells (Figures 6A and B). To better understand the effect of PROX1 up-regulation on viral RNA synthesis and replication, siRNA-mediated knockdown of PROX1 in BSR-T7/5 cells infected with rSS1GFP was investigated. Western blotting analysis confirmed that the expression of PROX1 was significantly decreased after transfection with PROX1 siRNA (Figure 6C). Meanwhile, knockdown of PROX1 reduced the relative levels of viral genomic RNA in rSS1GFP-infected cells at different time points, but the viral RNA levels in rSS1GFP-M/NLSm-infected cells were almost not affected (Figure 6D). Moreover, the virus titers of rSS1GFP in PROX1 siRNA-treated cells was much lower than that in control siRNA-treated cells, whereas the virus titers of rSS1GFP-M/NLSm was not changed in either PROX1 siRNA- or control siRNAtreated cells (Figure 6E). Together with the above results, these results indicate that up-regulation of PROX1 caused by the nuclear localization of $\mathrm{M}$ could efficiently enhance viral RNA synthesis and viral replication.

\section{Knockdown of AHR increases viral RNA synthesis and viral replication}

Aryl hydrocarbon receptor is a ligand-activated transcription factor, whose activation induces the expression of numerous genes and modulates host responses against viral infection [36, 37]. It is reported that AHR activation transcriptionally represses cyclin-dependent kinase (CDK) $1 / 2$ and their associated cyclins, thereby reducing cellular dNTP levels and both HIV-1 and HSV-1 replication [38]. Interestingly, the mRNA expression levels of AHR in rSS1GFP-infected cells showed a decreasing tendency at different time points, indicating that NDV replication needed the inactivation of AHR. Therefore, we first studied the role of AHR down-regulation in viral RNA synthesis and replication of NDV. Here, we found that the protein expression levels of AHR in rSS1GFPinfected or pCI-M-transfected cells were obviously decreased in comparison to that of AHR in rSS1GFP$\mathrm{M} / \mathrm{NLSm}$-infected or pCI-N/NLSm-transfected cells or normal cells (Figures 7A and B). We next evaluated the impact of AHR down-regulation on viral RNA synthesis and viral replication. siRNA-mediated knockdown of AHR shows that the expression level of AHR was significantly reduced in BSR-T7/5 cells when treated with AHR siRNA (Figure 7C). Accordingly, the viral RNA levels in rSS1GFP-infected cells were obviously increased at different time points, but the viral RNA levels in rSS 1GFP-M/NLSm-infected cells were nearly not affected (Figure 7D). In addition, the virus titers of rSS1GFP in AHR siRNA-treated cells was much higher than that in control siRNA-treated cells and normal cells, whereas both AHR siRNA- and control siRNA-treated cells had almost no effect on the virus titers of rSS1GFP-M/NLSm (Figure 7E). Together, the above results demonstrate that down-regulation of AHR caused by the nuclear localization of $M$ benefitted viral RNA synthesis and viral replication.

\section{Discussion}

With the co-evolution with their hosts for many years, viruses have developed very sophisticated strategies to hijack cellular factors that promote viral uptake, replication and spread $[39,40]$. Numerous reviews are now describing the interactions of various types of viral proteins with nuclear/nucleolar components, which take advantage of this specific localization to usurp one or more of its functions [41-43]. Like most cytoplasmic negative-sense RNA viruses, despite the paramyxoviruses complete viral RNA synthesis and replication in 
A

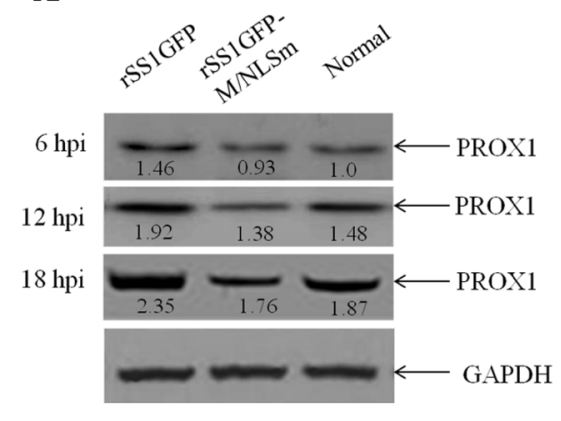

B

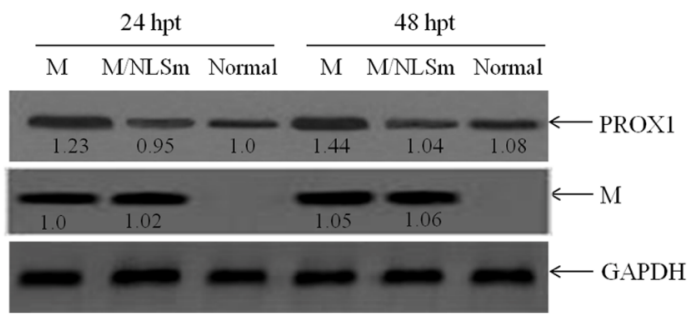

C

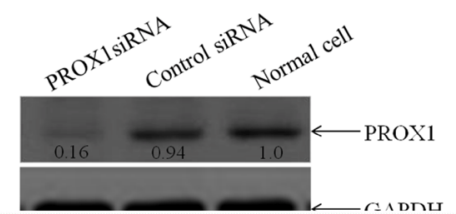

D
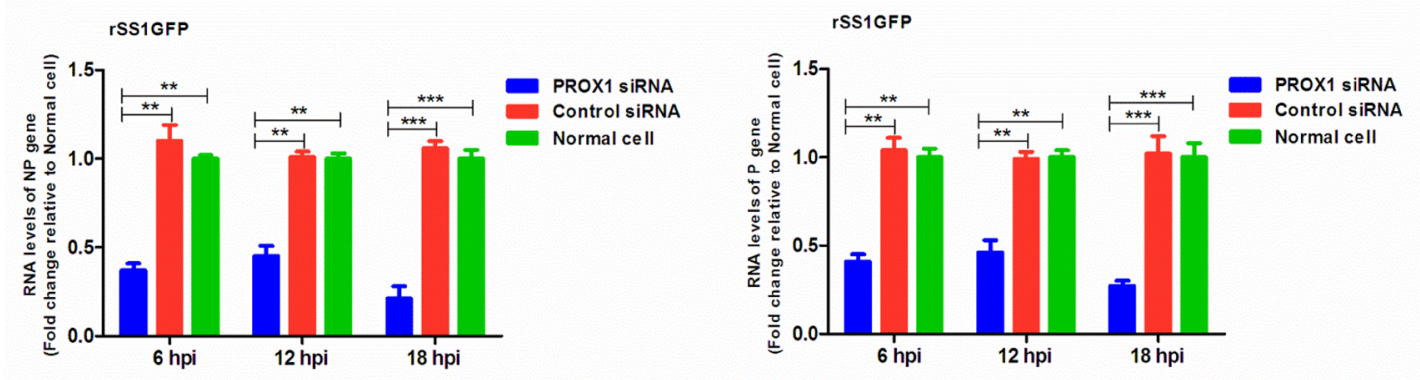

rSS1GFP-M/NLSm

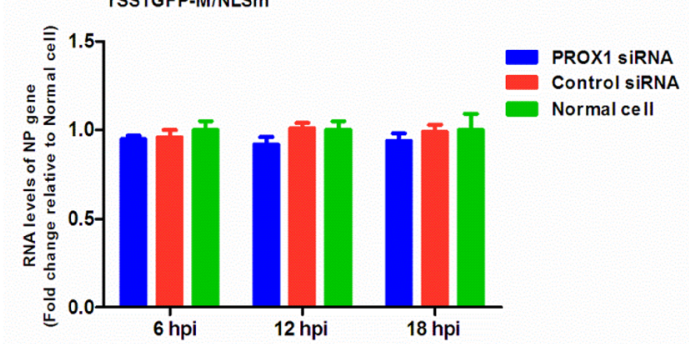

rSS1GFP-M/NLSm

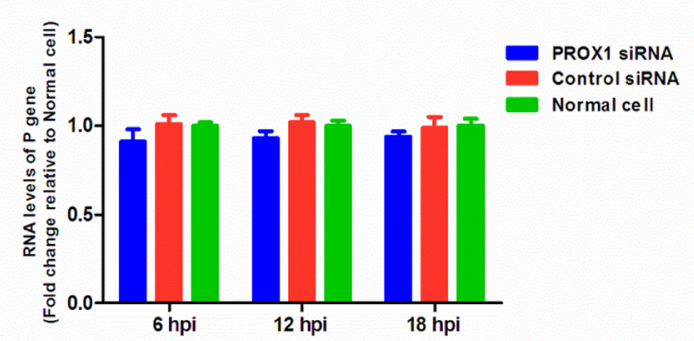

E

ISS1GFP

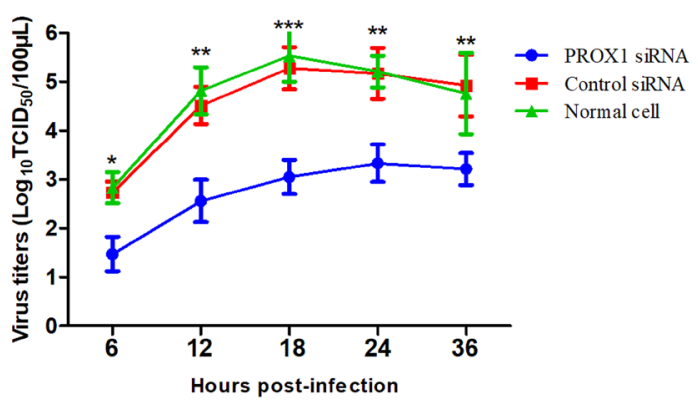

rSS1GFP-M/NLSm

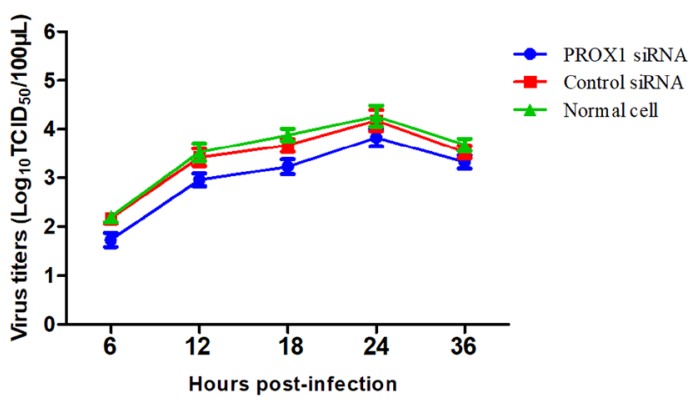

Figure 6 Effect of PROX1 knockdown on the viral RNA synthesis and viral replication. The expression levels of PROX1 protein in BSR-T7/5 cells infected with rSS1GFP and rSS1 GFP-M/NLSm (A) or transfected with pCI-M and pCI-M/NLSm (B) were examined by Western blotting. The relative levels of the PROX1 protein were compared with the control GAPDH expression. $\mathbf{C}$ Effect of the PROX1 siRNA or control siRNA on the expression of endogenous PROX1 in BSR-T7/5 cells. D PROX1 siRNA- or control siRNA-treated BSR-T7/5 cells were infected with rSS1GFP and rSS1GFP-M/ NLSm, and viral RNA synthesis corresponding to the NP and P genes were detected by qRT-PCR. E The growth kinetics of rSS1GFP and rSS1GFP-M/ NLSm were compared using multicycle growth curves in PROX1 siRNA- or control siRNA-treated cells. Error bars represent standard deviations (mean \pm SD) $\left({ }^{*} P<0.05 ; * * P<0.01 ; * * P<0.001\right.$ compared to the value of rSS1GFP-M/NLSm). 
A

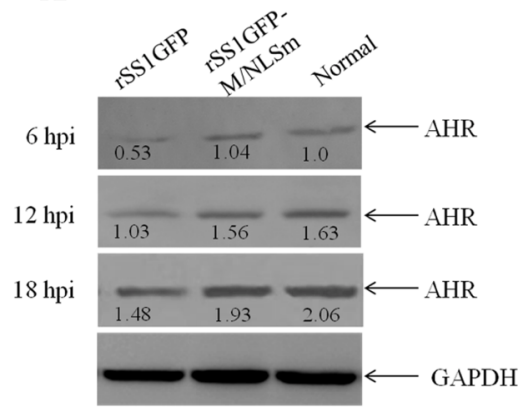

B

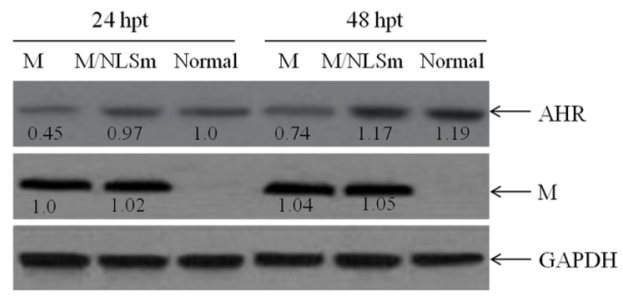

C

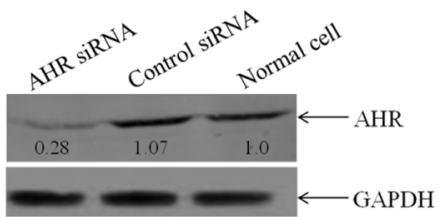

D
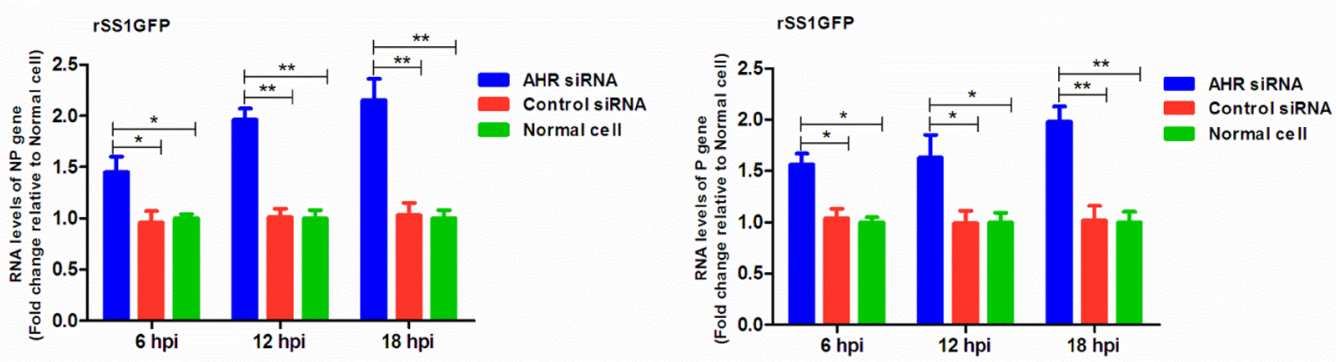

rSS1GFP-M/NLSm

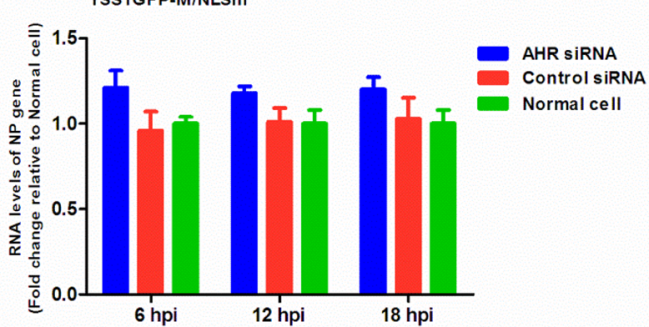

rSS1GFP-M/NLSm

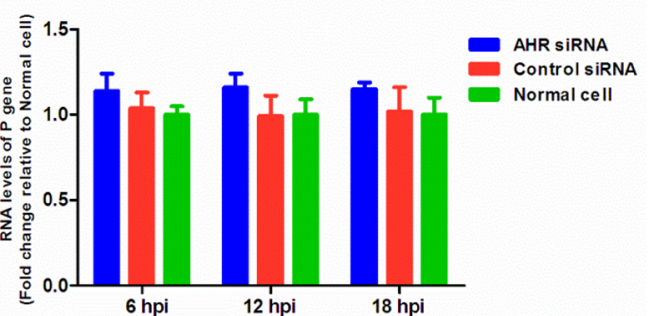

E

rSS1GFP

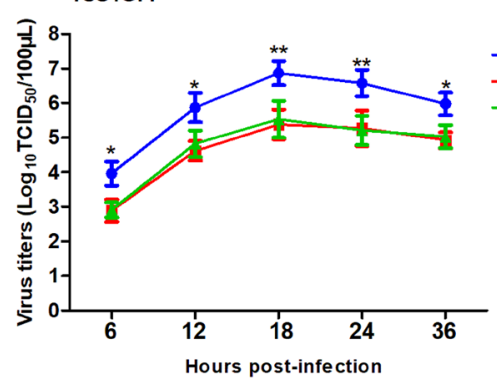

rSS1GFP-M/NLSm

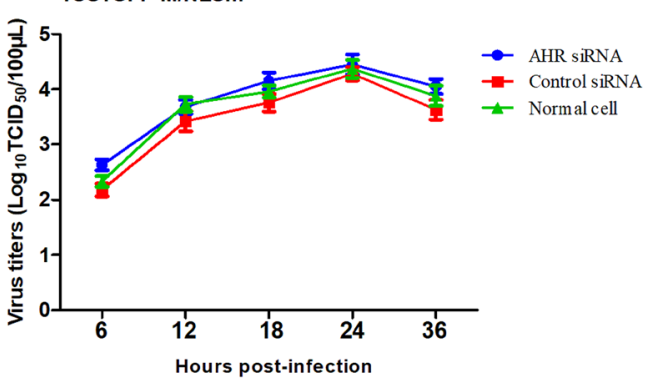

Figure 7 Effect of AHR knockdown on the viral RNA synthesis and viral replication. The expression levels of AHR protein in BSR-T7/5 cells infected with rSS1GFP and rSS1GFP-M/NLSm (A) or transfected with pCI-M and pCI-M/NLSm (B) were examined by Western blotting. The relative levels of the AHR protein were compared with the control GAPDH expression. C Effect of the AHR siRNA or control siRNA on the expression of endogenous AHR in BSR-T7/5 cells. D AHR siRNA- or control siRNA-treated BSR-T7/5 cells were infected with rSS1GFP and rSS1GFP-M/NLSm, and viral RNA synthesis corresponding to the NP and P genes were detected by qRT-PCR. E The growth kinetics of rSS1GFP and rSS1GFP-M/NLSm were compared using multicycle growth curves in AHR siRNA- or control siRNA-treated cells. Error bars represent standard deviations (mean \pm SD) $\left({ }^{*} P<0.05 ;{ }^{*} P<0.01 ;{ }^{* * *} P<0.001\right.$ compared to the value of rSS1GFP-M/NLSm). 
the cytoplasm, some viral proteins are localized in the nucleus at early stages of virus infection, such as the $M$ protein of $\mathrm{NiV}, \mathrm{SeV}, \mathrm{NDV}, \mathrm{MeV}$ and $\mathrm{MuV}$, or the NP protein of $\mathrm{MeV}$ [5]. Up to now, several lines of evidence have demonstrated that the $M$ protein of paramyxoviruses is a nucleocytoplasmic trafficking protein and plays essential roles in the virus life cycle $[3,5,44]$. It is noteworthy that the nuclear localization function of NNSV M protein has only been reported in HRSV [8], VSV [9, 10], and paramyxovirus $\mathrm{MeV}$ [11], showing the capability of inhibiting host cell transcription independently of other viral components. As an important member of the NNSV, nuclear localization of NDV M protein is thought to alter some nuclear components required for the synthesis of host transcripts, because NDV is the most effective paramyxovirus at inhibiting the production of host proteins [45]. However, the exact effect of $M$ protein in the nucleus on the cellular nuclear functions and the replication of NDV still remains unclear.

In our studies, we first examined the dynamic changes of the intracellular localization of $\mathrm{M}$ for rSS1GFP and rSS1GFP-M/NLSm. In contrast to the nucleocytoplasmic shuttling of rSS1GFP $M$ protein, the $M$ protein of rSS1GFP-M/NLSm localized primarily around the nucleus early in infection and then distributed diffusely in the cytoplasm later in infection (Figures $1 \mathrm{~A}$ and B). The reason for this localization pattern changes in $\mathrm{M} /$ NLSm protein might be that the M/NLS mutation disrupted importin $\beta 1$-mediated nuclear import of the $M$ protein [22] and caused the localization of $M$ protein around the nucleus at $6 \mathrm{hpi}$. Meanwhile, due to the interactions of $\mathrm{M}-\mathrm{HN}$ and $\mathrm{M}-\mathrm{NP}$ and the role of M protein in virion assembly and budding, more M/NLSm protein might remain and distribute diffusely in the cytoplasm at 12 and $18 \mathrm{hpi}$. It has been shown that NLS-mediated nuclear localization of viral protein plays crucial roles in regulating viral replication and in evading host immunity. For example, NLS mutation in the core protein of Japanese encephalitis virus (JEV) reduces both the virus replication in mammalian cells in vitro and the pathogenesis of encephalitis induced by JEV in vivo [46]. Similarly, nuclear localized influenza A virus (IAV) nucleoprotein $\mathrm{N}$-terminal deletion mutant is deficient in viral mRNA translation and exhibits a defect in functional viral ribonucleoprotein formation, which causes a delay in the replication of IAV infected cells [47]. In addition, recent studies have also indicated that nuclear import of rabies virus $P$ protein is beneficial for inhibiting host gene transcription, regulating viral genome replication and transcription, and disrupting antiviral signaling pathways [48, 49]. Correspondingly, we previously demonstrated that NLS mutation in the M protein not only impairs the replication efficiency and plaque formation ability of NDV in DF-1 cells, but also attenuates the replication and pathogenicity of NDV in SPF chickens [22]. Here, we also found that M/NLS mutation markedly reduced both the cytopathogenicity and the syncytium formation of NDV (Figures $1 \mathrm{C}$ and D). There were two possible explanations for this. One reason was that rSS1GFP replicated faster and led to faster $\mathrm{F}$ protein expression, which directly caused cell fusion. Another reason was that the rSS1GFPM/NLSm M protein was cytoplasmic, where it could bind to F cytoplasmic tails and restrict its fusion activity, while the rSS1GFP M protein was nuclear and separated from $\mathrm{F}$ protein at the early time points. Together, these findings indicated that nuclear targeting of $M$ protein could be a key step in the replication and pathogenicity of NDV.

Based on the findings from NNSV such as HRSV, VSV and $\mathrm{SeV}$, the $\mathrm{M}$ protein is demonstrated to inhibit transcriptase activity through $\mathrm{M}-\mathrm{NP}$ interaction early in infection, and thereby repress the signal to switch from transcription to packaging into the virion particle $[8,50,51]$. Supporting this conclusion is the fact that $\mathrm{SeV}$ M protein can be cross-linked to the NP protein in new generated virions [52], and the addition of $\mathrm{M}$ protein to VSV and SeV nucleocapsids decreases their ability to transcribe viral RNA $[50,53]$. The NDV M protein is shown to directly interact with viral HN and NP proteins, which are responsible for the incorporation of $\mathrm{HN}$ and NP proteins into virus-like particles [6]. Interestingly, we also found that M/NLS mutation reduced the viral RNA synthesis and transcription efficiency either in the minigenome assays or in viruses-infected cells (Figures 2 and 3), indicating that precocious cytoplasmic $M$ protein had a negative effect on viral RNA synthesis and transcription. Because the NNSV M protein has the ability to inhibit viral transcriptase activity of the nucleocapsid prior to packaging and to mediate the association of the nucleocapsid with the nascent viral envelope in the later stages of virus infection $[54,55]$, we concluded that early accumulation of NDV M protein in the nucleus might ensure that viral RNA replication and transcription in the cytoplasm proceeded smoothly until a certain level of viral RNA and protein expression was reached, at which point the $\mathrm{M}$ protein could then be transported into the cytoplasmic and cell membrane to associate with the nucleocapsids for virus assembly and budding.

Numerous studies have revealed that the host response contributes to viral replication and pathogenesis [56-60]. Thus, we further elucidated the contribution of host transcriptional response to the difference in cells infected with rSS1GFP and rSS1GFP-M/NLSm. The global gene expression profile indicates that rSS1GFP greatly influenced host response, as evidenced by a larger amount of differentially expressed genes involved in binding, catalytic activity, 


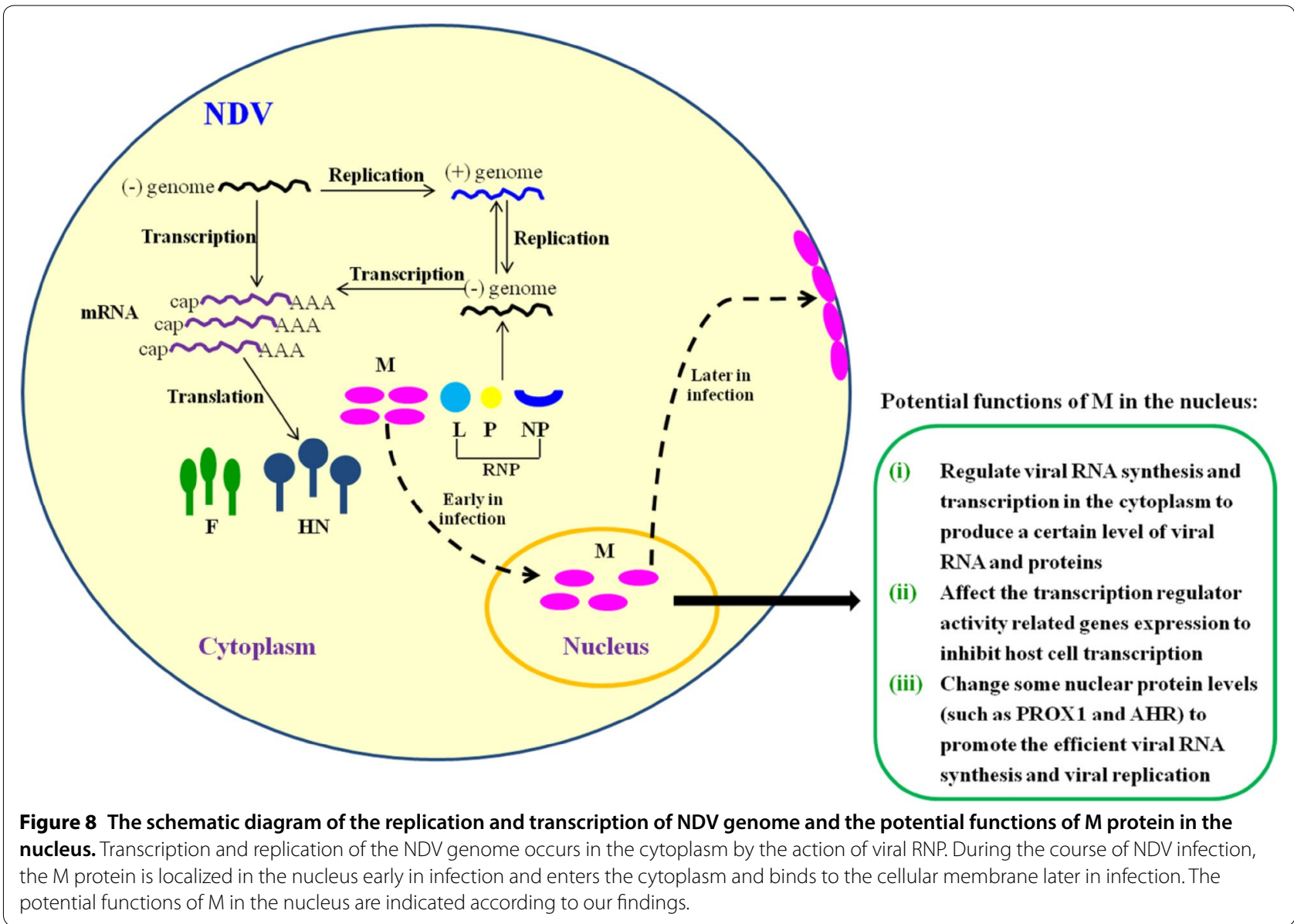

transcription regulator activity, molecular function regulator and transporter activity (Figure 4). Functional and canonical analysis using IPA reveals that rSS1GFP actively motivated virus infection-induced signaling pathways (Table 2). Of all these pathways, rSS1GFP infection obviously caused the signaling pathway of transcriptional misregulation at 12 and $18 \mathrm{hpi}$ (Additional file 2), suggesting that nuclear localization of $M$ protein affected the process of host cell transcription. Remarkably, one of the most important findings of our study was that nuclear localization of NDV M protein inhibited host cell transcription, showing that most up-regulated genes were associated with transcription repressor activity and negative regulation of transcription, whereas the down-regulated genes were involved in DNA binding or RNA polymerase II transcription factor activity and transcriptional activator activity (Figure 5, Tables 3 and 4). For the investigation of nuclear localization functions of NNSV M protein, a previous study has shown that nuclear extracts from HRSVinfected cells have less transcriptional activity in vitro and inhibit the transcriptional activity of nuclear extracts from mock-infected cells, suggesting that HRSV M protein plays a role in inhibiting host cell transcription [28]. In addition, a recent study has demonstrated that transient expression of $\mathrm{MeV} \mathrm{M}$ protein in transfected cells inhibits cellular transcription via binding to nuclear factors [11]. Additionally, the $M$ protein is able to inhibit in vitro transcription in a dose-dependent manner, indicating the role of $\mathrm{MeV}$ $M$ in inhibiting host cell transcription [11]. Moreover, studies focusing on VSV M protein revealed that M protein directly inhibits host cell transcription by inactivating essential transcription factors [9], and also inhibits cellular nuclear transport to impair mRNA export, indirectly leading to a decrease and an increase in host cell and virus transcription [30, 61, 62]. Based on the results of microarray analysis, we speculated that NDV M protein possibly hijacked the expression of transcription regulator activity related genes to affect host mRNA synthesis, which in turn effected the inhibition of host cell transcription. Together, the above findings suggest that the inhibition of host cell transcription caused by the nuclear localization of $M$ in NNSV could occur through diverse pathways.

It is notable that virus-host interactions will greatly improve our understanding of the replication and 
pathogenesis of viruses. Therefore, we further investigated the role of the selected up-regulated gene PROX1 and down-regulated gene AHR in the viral RNA synthesis and replication of NDV. It is reported that PROX1 and AHR genes are a kind of transcription factors that play essential roles in cell life activities, and more importantly, the up-regulation of PROX1 or down-regulation of AHR has been reported to be beneficial for virus replication found in KSHV [35] or HIV-1 and HSV-1 infection [38]. In our studies, we also found that the expression levels of PROX1 and AHR proteins were obviously increased or decreased in rSS1GFP-infected cells or pCI-M-transfected cells (Figures 6A, B and 7A, B), which was consistent with the results of qRT-PCR (Figures $5 \mathrm{C}$ and D). Remarkably, cells transfected to express viral NP or HN protein had no effect on the expression levels of PROX1 and AHR (data not shown), indicating that nuclear localization of $M$ protein played important roles in regulating this process. In addition, siRNA-mediated knockdown of PROX1 or AHR significantly reduced or increased the viral RNA levels and virus replication ability (Figures 6D, $\mathrm{E}$ and $7 \mathrm{D}, \mathrm{E})$, respectively, suggesting the important roles of the expression level changes of PROX1 and AHR in the NDV life cycle. However, how M protein affects the expression of PROX1 and AHR and what the specific roles of PROX1 and AHR in the replication of NDV are currently unknown. Further investigation into the signaling pathways that are involved in their interactions and functions are needed to gain a better understanding of the underlying replication of NDV. In summary, our findings reveal for the first time the potential functions of NDV M protein in the nucleus (Figure 8), which will provide foundations for investigating the role of $\mathrm{M}$ protein in the replication and pathogenesis of NDV and other paramyxoviruses.

\section{Additional files}

Additional file 1. Schematic representation of viral RNA synthesis and GFP reporter gene translation in the minigenome system. BSR-T7/5 cells were co-transfected with a minigenome plasmid pTVTLGT, helper plasmids pCI-NP, pCI-P, pCI-L and pCI-M or pCI-M/NLSm. Antigenomic, positive-sense minigenome RNA (gRNA[+]) was transcribed from the minigenomic plasmid by T7 RNA polymerase. In the presence of $N P, P$ and $L, g R N A(+)$ acted as a template for the transcription of genomic RNA (gRNA[-]), which generated GFP reporter gene mRNA and more gRNA(+).

Additional file 2. Modeling of the signaling pathway of transcriptional misregulation in DF-1 cells infected with rSS1GFP at $12 \mathrm{hpi}(\mathrm{A})$ and $18 \mathrm{hpi}$ (B). The signaling pathway of transcriptional misregulation induced by rSS1GFP infection was drawn, and the significantly differentially expressed genes involved in this pathway are indicated: a red label indicates up-regulated genes; a green label indicates down-regulated genes.

\section{Competing interests}

The authors declare that they have no competing interests.

\section{Authors' contributions}

$\mathrm{ZD}$ and $\mathrm{XJ}$ conceived and designed this experiment and wrote the manuscript. SD, CY and HG performed the experiments. JZ performed statistics analysis and interpretation. All authors read and approved the final manuscript.

\section{Acknowledgements}

This study was supported by the National Natural Science Foundation of China (31760732 and 31502074), the Science and Technology Project of Guizhou Province (QKH-2017-5788), the Provincial Nation-class Discipline of Biology Foundation (GNYL-2017-009), the Scientific Research Cooperation Project with America and Oceania Region, Ministry of Education (JWSM2014-2029), and the Agricultural Research Project of Guizhou Province (QKHZC-2016-2588).

\section{Author details}

${ }^{1}$ Key Laboratory of Animal Genetics, Breeding and Reproduction in The Plateau Mountainous Region, Ministry of Education, Guizhou University, Guiyang, China. ${ }^{2}$ College of Animal Science, Guizhou University, Guiyang, China.

\section{Publisher's Note}

Springer Nature remains neutral with regard to jurisdictional claims in published maps and institutional affiliations.

Received: 31 October 2018 Accepted: 11 February 2019

Published online: 20 March 2019

\section{References}

1. Jordan PC, Liu C, Raynaud P, Lo MK, Spiropoulou CF, Symons JA, Beigelman L, Deval J (2018) Initiation, extension, and termination of RNA synthesis by a paramyxovirus polymerase. PLoS Pathog 14:e1006889

2. El Najjar F, Schmitt AP, Dutch RE (2014) Paramyxovirus glycoprotein incorporation, assembly and budding: a three way dance for infectious particle production. Viruses 6:3019-3054

3. Noton SL, Fearns R (2015) Initiation and regulation of paramyxovirus transcription and replication. Virology 479:545-554

4. Battisti AJ, Meng G, Winkler DC, McGinnes LW, Plevka P, Steven AC, Morrison TG, Rossmann MG (2012) Structure and assembly of a paramyxovirus matrix protein. Proc Natl Acad Sci USA 109:13996-14000

5. Audsley MD, Jans DA, Moseley GW (2016) Roles of nuclear trafficking in infection by cytoplasmic negative-strand RNA viruses: paramyxoviruses and beyond. J Gen Virol 97:2463-2481

6. Pantua HD, McGinnes LW, Peeples ME, Morrison TG (2006) Requirements for the assembly and release of Newcastle disease virus-like particles. J Virol 80:11062-11073

7. Ke ZL, Strauss JD, Hampton CM, Brindley MA, Dillard RS, Leon F, Lamb KM, Plemper RK, Wright ER (2018) Promotion of virus assembly and organization by the measles virus matrix protein. Nat Commun 9:1736

8. Ghildyal R, Ho A, Jans DA (2006) Central role of the respiratory syncytial virus matrix protein in infection. FEMS Microbiol Rev 30:692-705

9. Ahmed M, Lyles DS (1998) Effect of vesicular stomatitis virus matrix protein on transcription directed by host RNA polymerases I, II, and III. J Virol 72:8413-8419

10. Ahmed M, McKenzie MO, Puckett S, Hojnacki M, Poliquin L, Lyles DS (2003) Ability of the matrix protein of vesicular stomatitis virus to suppress beta interferon gene expression is genetically correlated with the inhibition of host RNA and protein synthesis. J Virol 77:4646-4657

11. Yu XL, Shahriari S, Li HM, Ghildyal R (2016) Measles virus matrix protein inhibits host cell transcription. PLoS One 11:e0161360

12. Ganar K, Das M, Sinha S, Kumar S (2014) Newcastle disease virus: current status and our understanding. Virus Res 184:71-81

13. Miller PJ, Decanini EL, Afonso CL (2010) Newcastle disease: evolution of genotypes and the related diagnostic challenges. Infect Genet Evol 10:26-35 
14. Dortmans JCFM, Koch G, Rottier PJM, Peeters BPH (2011) Virulence of Newcastle disease virus: what is known so far? Vet Res 42:122

15. Cheng JH, Sun YJ, Zhang FQ, Zhang XR, Qiu XS, Yu LP, Wu YT, Ding C (2016) Newcastle disease virus NP and P proteins induce autophagy via the endoplasmic reticulum stress-related unfolded protein response. Sci Rep 6:24721

16. Yu XH, Cheng JL, He ZR, Li C, Song Y, Xue J, Yang HM, Zhang R, Zhang GZ (2017) The glutamic residue at position 402 in the C-terminus of Newcastle disease virus nucleoprotein is critical for the virus. Sci Rep 7:17471

17. Duan Z, Hu Z, Zhu J, Xu H, Chen J, Liu H, Hu S, Liu X (2014) Mutations in the FPIV motif of Newcastle disease virus matrix protein attenuate virus replication and reduce virus budding. Arch Virol 159:1813-1819

18. Xu HX, Duan ZQ, Chen Y, Liu JJ, Cheng X, Liu JJ, Zhu J, Wang XQ, Liu XW, Hu SL, Liu XF (2016) Simultaneous mutation of G275A and P276A in the matrix protein of Newcastle disease virus decreases virus replication and budding. Arch Virol 161:3527-3533

19. McGinnes LW, Morrison TG (2013) Newcastle disease virus-like particles: preparation, purification, quantification, and incorporation of foreign glycoproteins. Curr Protoc Microbiol 30(18):2

20. Li X, Li X, Cao H, Wang Y, Zheng SJ (2013) Engagement of new castle disease virus (NDV) matrix (M) protein with charged multivesicular body protein (CHMP) 4 facilitates viral replication. Virus Res 171:80-88

21. Duan Z, Chen J, Xu H, Zhu J, Li Q, He L, Liu H, Hu S, Liu X (2014) The nucleolar phosphoprotein B23 targets Newcastle disease virus matrix protein to the nucleoli and facilitates viral replication. Virology 452-453:212-222

22. Duan ZQ, Xu HX, Ji XQ, Zhao JF, Xu HQ, Hu Y, Deng SS, Hu SL, Liu XF (2018) Importin a5 negatively regulates importin $\beta 1$-mediated nuclear import of Newcastle disease virus matrix protein and viral replication and pathogenicity in chicken fibroblasts. Virulence 9:783-803

23. Molouki A, Hsu YT, Jahanshiri F, Abdullah S, Rosli R, Yusoff K (2011) The matrix (M) protein of Newcastle disease virus binds to human bax through its BH3 domain. Virol J 8:385

24. Giuffre RM, Tovell DR, Kay CM, Tyrrell DL (1982) Evidence for an interaction between the membrane protein of a paramyxovirus and actin. J Virol 42:963-968

25. Coleman NA, Peeples ME (1993) The matrix protein of Newcastle disease virus localizes to the nucleus via a bipartite nuclear localization signal. Virology 195:596-607

26. Huang M, Sato H, Hagiwara K, Watanabe A, Sugai A, Ikeda F, Kozuka-Hata H, Oyama M, Yoneda M, Kai C (2011) Determination of a phosphorylation site in Nipah virus nucleoprotein and its involvement in virus transcription. J Gen Virol 92:2133-2141

27. Qiu X, Zhan Y, Meng C, Wang J, Dong L, Sun Y, Tan L, Song C, Yu S, Ding C (2016) Identification and functional analysis of phosphorylation in Newcastle disease virus phosphoprotein. Arch Virol 161:2103-2116

28. Ghildyal R, Baulch-Brown C, Mills J, Meanger J (2003) The matrix protein of human respiratory syncytial virus localises to the nucleus of infected cells and inhibits transcription. Arch Virol 148:1419-1429

29. Rajani KR, Kneller ELP, McKenzie MO, Horita DA, Chou JW, Lyles DS (2012) Complexes of vesicular stomatitis virus matrix protein with host Rae1 and Nup98 involved in inhibition of host transcription. PLoS Pathog 8:e1002929

30. Pan W, Song DG, He WQ, Lu HJ, Lan YG, Tong JZ, Gao F, Zhao K (2017) The matrix protein of vesicular stomatitis virus inhibits host-directed transcription of target genes via interaction with the TFIIH subunit p8. Vet Microbiol 208:82-88

31. Wigle JT, Oliver G (1999) Prox1 function is required for the development of the murine lymphatic. Cell 98:769-778

32. Sosa-Pineda B, Wigle JT, Oliver G (2000) Hepatocyte migration during liver development requires Prox1. Nat Genet 25:254-255

33. Lavado A, Oliver G (2007) Prox1 expression patterns in the developing and adult murine brain. Dev Dyn 236:518-524

34. Gill HK, Parsons SR, Spalluto C, Davies AF, Knorz V, Burlinson CE, Ng BL, Carter NP, Ogilvie CM, Wilson DI, Roberts RG (2009) Separation of the PROX1 gene from upstream conserved elements in a complex inversion/translocation patient with hypoplastic left heart. Eur J Hum Genet 17:1423-1431

35. Yoo J, Kang J, Lee HN, Aguilar B, Kafka D, Lee S, Choi I, Lee J, Ramu S, Haas J, Koh CJ, Hong YK (2010) Kaposin-B enhances the PROX1 mRNA stability during lymphatic reprogramming of vascular endothelial cells by Kaposi's sarcoma herpes virus. PLoS Pathog 6:e1001046
36. Head JL, Lawrence BP (2009) The aryl hydrocarbon receptor is a modulator of anti-viral immunity. Biochem Pharmacol 77:642-653

37. Gutierrez-Vazquez C, Quintana FJ (2018) Regulation of the immune response by the aryl hydrocarbon receptor. Immunity 48:19-33

38. Kueck T, Cassella E, Holler J, Kim B, Bieniasz PD (2018) The aryl hydrocarbon receptor and interferon gamma generate antiviral states via transcriptional repression. Elife 7:e38867

39. Smyth RP, Negroni M, Lever AM, Mak J, Kenyon JC (2018) RNA structurea neglected puppet master for the evolution of virus and host immunity. Front Immunol 9:2097

40. Sakaguchi S, Chida J (2018) Roles of prion protein in virus infections. DNA Cell Biol 37:808-811

41. Rawlinson SM, Moseley GW (2015) The nucleolar interface of RNA viruses. Cell Microbiol 17:1108-1120

42. Wulan WN, Heydet D, Walker EJ, Gahan ME, Ghildyal R (2015) Nucleocytoplasmic transport of nucleocapsid proteins of enveloped RNA viruses. Front Microbiol 6:553

43. Fay N, Pante N (2015) Old foes, new understandings: nuclear entry of small non-enveloped DNA viruses. Curr Opin Virol 12:59-65

44. Watkinson RE, Lee B (2016) Nipah virus matrix protein: expert hacker of cellular machines. FEBS Lett 590:2494-2511

45. Hightower LE, Bratt MA (1974) Protein synthesis in Newcastle disease virus-infected chicken embryo cells. J Virol 13:788-800

46. Mori Y, Okabayashi T, Yamashita T, Zhao Z, Wakita T, Yasui K, Hasebe F, Tadano M, Konishi E, Moriishi K, Matsuura Y (2005) Nuclear localization of Japanese encephalitis virus core protein enhances viral replication. J Virol 79:3448-3458

47. Sanchez A, Guerrero-Juarez CF, Ramirez J, Newcomb LL (2014) Nuclear localized influenza nucleoprotein $\mathrm{N}$-terminal deletion mutant is deficient in functional vRNP formation. Virol J 11:155

48. Oksayan S, Wiltzer L, Rowe CL, Blondel D, Jans DA, Moseley GW (2012) A novel nuclear trafficking module regulates the nucleocytoplasmic localization of the rabies virus interferon antagonist, $\mathrm{P}$ protein. J Biol Chem 287:28112-28121

49. Rowe CL, Wagstaff KM, Oksayan S, Glover DJ, Jans DA, Moseley GW (2016) Nuclear trafficking of the rabies virus interferon antagonist P-protein is regulated by an importin-binding nuclear localization sequence in the C-terminal domain. PLoS One 11:e0150477

50. Marx PA, Portner A, Kingsbury DW (1974) Sendai virion transcriptase complex: polypeptide composition and inhibition by virion envelope proteins. J Virol 13:107-112

51. Clinton GM, Little SP, Hagen FS, Huang AS (1978) The matrix (M) protein of vesicular stomatitis virus regulates transcription. Cell 15:1455-1462

52. Markwell MA, Fox CF (1980) Protein-protein interactions within paramyxoviruses identified by native disulfide bonding or reversible chemical cross-linking. J Virol 33:152-166

53. Carroll AR, Wagner RR (1979) Role of the membrane (M) protein in endogenous inhibition of in vitro transcription by vesicular stomatitis virus. J Virol 29:134-142

54. Iwasaki M, Takeda M, Shirogane Y, Nakatsu Y, Nakamura T, Yanagi Y (2009) The matrix protein of measles virus regulates viral RNA synthesis and assembly by interacting with the nucleocapsid protein. J Virol 83:10374-10383

55. Ghildyal R, Mills J, Murray M, Vardaxis N, Meanger J (2002) Respiratory syncytial virus matrix protein associates with nucleocapsids in infected cells. J Gen Virol 83:753-757

56. Liu WW, Qiu XS, Song CP, Sun YJ, Meng CC, Liao Y, Tan L, Ding Z, Liu XF, Ding C (2018) Deep sequencing-based transcriptome profiling reveals avian interferon-stimulated genes and provides comprehensive insight into Newcastle disease virus-induced host responses. Viruses 10:E162

57. Hu ZL, Hu J, Hu SL, Song QQ, Ding PY, Zhu J, Liu XW, Wang XQ, Liu XF (2015) High levels of virus replication and an intense inflammatory response contribute to the severe pathology in lymphoid tissues caused by Newcastle disease virus genotype VIld. Arch Virol 160:639-648

58. Kosch R, Delarocque J, Claus P, Becker SC, Jung K (2018) Gene expression profiles in neurological tissues during West Nile virus infection: a critical meta-analysis. BMC Genom 19:530

59. Yang XX, Xie J, Jia LL, Liu N, Liang Y, Wu FL, Liang BB, Li YR, Wang JY, Sheng CY, Li H, Liu HB, Ma QX, Yang CJ, Du XY, Qiu SF, Song HB (2017) Analysis of miRNAs involved in mouse brain damage upon enterovirus 71 infection. Front Cell Infect Microbiol 7:133 
60. Nakamura S, Horie M, Daidoji T, Honda T, Yasugi M, Kuno A, Komori T, Okuzaki D, Narimatsu H, Nakaya T, Tomonaga K (2016) Influenza A virusinduced expression of a GalNAc transferase, GALNT3, via microRNAs is required for enhanced viral replication. J Virol 90:1788-1801

61. Faria PA, Chakraborty P, Levay A, Barber GN, Ezelle HJ, Enninga J, Arana C, van Deursen J, Fontoura BM (2005) VSV disrupts the Rae1/mrnp41 mRNA nuclear export pathway. Mol Cell 17:93-102
62. von Kobbe C, van Deursen JM, Rodrigues JP, Sitterlin D, Bachi A, Wu X Wilm M, Carmo-Fonseca M, Izaurralde E (2000) Vesicular stomatitis virus matrix protein inhibits host cell gene expression by targeting the nucleoporin Nup98. Mol Cell 6:1243-1452
Ready to submit your research? Choose BMC and benefit from:

- fast, convenient online submission

- thorough peer review by experienced researchers in your field

- rapid publication on acceptance

- support for research data, including large and complex data types

- gold Open Access which fosters wider collaboration and increased citations

- maximum visibility for your research: over $100 \mathrm{M}$ website views per year

At BMC, research is always in progress.

Learn more biomedcentral.com/submissions 